\title{
The role of vibrationally excited oxygen and nitrogen in the ionosphere during the undisturbed and geomagnetic storm period of 6-12 April 1990
}

\author{
A. V. Pavlov \\ Institute of Terrestrial Magnetism, Ionosphere and Radio-Wave Propagation, Russia Academy of Science (IZMIRAN), Troitsk, Moscow \\ Region, 142092, Russia Fax: +7 095 3340124; e-mail: pavlov@charley.izmiran.rssi.ru
}

Received: 24 July 1997 / Revised: 28 November 1997 / Accepted: 2 December 1997

\begin{abstract}
We present a comparison of the observed behavior of the F-region ionosphere over Millstone Hill during the geomagnetically quiet and storm periods of 6-12 April 1990 with numerical model calculations from the IZMIRAN time-dependent mathematical model of the Earth's ionosphere and plasmasphere. The major enhancement to the IZMIRAN model developed in this study is the use of a new loss rate of $\mathrm{O}^{+}\left({ }^{4} \mathrm{~S}\right)$ ions as a result of new high-temperature flowing afterglow measurements of the rate coefficients $K_{1}$ and $K_{2}$ for the reactions of $\mathrm{O}^{+}\left({ }^{4} \mathrm{~S}\right)$ with $\mathrm{N}_{2}$ and $\mathrm{O}_{2}$. The deviations from the Boltzmann distribution for the first five vibrational levels of $\mathrm{O}_{2}(v)$ were calculated, and the present study suggests that these deviations are not significant. It was found that the difference between the non-Boltzmann and Boltzmann distribution assumptions of $\mathrm{O}_{2}(v)$ and the difference between ion and neutral temperature can lead to an increase of up to about $3 \%$ or a decrease of up to about $4 \%$ of the calculated $\mathrm{NmF} 2$ as a result of a respective increase or a decrease in $K_{2}$. The IZMIRAN model reproduces major features of the data. We found that the inclusion of vibrationally excited $\mathrm{N}_{2}(v>0)$ and $\mathrm{O}_{2}(v>0)$ in the calculations improves the agreement between the calculated NmF2 and the data on 6, 9, and 10 April. However, both the daytime and nighttime densities are reproduced by the IZMIRAN model without the vibrationally excited nitrogen and oxygen on 8 and 11 April better than the IZMIRAN model with $\mathrm{N}_{2}(v>0)$ and $\mathrm{O}_{2}(v>0)$. This could be due to possible uncertainties in model neutral temperature and densities, EUV fluxes, rate coefficients, and the flow of ionization between the ionosphere and plasmasphere, and possible horizontal divergence of the flux of ionization above the station. Our calculations show that the increase in the $\mathrm{O}^{+}+\mathrm{N}_{2}$ rate factor due to $\mathrm{N}_{2}(v>0)$ produces a 5$36 \%$ decrease in the calculated daytime peak density. The increase in the $\mathrm{O}^{+}+\mathrm{O}_{2}$ loss rate due to vibrationally excited $\mathrm{O}_{2}$ produces $8-46 \%$ reductions in $\mathrm{NmF}$. The effects of vibrationally excited $\mathrm{O}_{2}$ and $\mathrm{N}_{2}$ on $N_{e}$ and $T_{e}$ are most pronounced during the daytime.
\end{abstract}

Key words. Ion chemistry and composition . Ionosphere - atmosphere interactions - Ionospheric disturbances

\section{Introduction}

In modeling the ionosphere it is necessary to know the loss rate of $\mathrm{O}^{+}\left({ }^{4} \mathrm{~S}\right)$ ions. The most important chemical processes in determining the abundance of $\mathrm{O}^{+}\left({ }^{4} \mathrm{~S}\right)$ ions are the reactions

$$
\begin{aligned}
& \mathrm{O}^{+}\left({ }^{4} \mathrm{~S}\right)+\mathrm{N}_{2}(v) \rightarrow \mathrm{NO}^{+}+\mathrm{N}, \\
& \mathrm{O}^{+}\left({ }^{4} \mathrm{~S}\right)+\mathrm{O}_{2}(v) \rightarrow \mathrm{O}_{2}^{+}+\mathrm{O},
\end{aligned}
$$

where $v=0,1, \ldots$ is the number of the vibrational level of $\mathrm{N}_{2}$ or $\mathrm{O}_{2}$.

The rate coefficients of $\mathrm{O}^{+}\left({ }^{4} \mathrm{~S}\right)$ ions with $\mathrm{N}_{2}(v>0)$ were measured by Schmeltekopf et al. (1968) for $T_{n}=T_{i}=300 \mathrm{~K}$ (where $T_{n}$ is the neutral temperature and $T_{i}$ is the ion temperature) and were confirmed by Ferguson et al. (1984). The measurements of the effective rate coefficient for the reaction of $\mathrm{O}^{+}\left({ }^{4} \mathrm{~S}\right)$ with $\mathrm{N}_{2}$ was given by Hierl et al. (1997) over the temperature range $300-1600 \mathrm{~K}$ for $T_{n}=T_{i}=T_{v}$, where $T_{v}$ is the vibrational temperature of $\mathrm{N}_{2}$. These results confirm the observations of Schmeltekopf et al. (1968) and show that the assumption of similar translation temperature dependencies for different states is reasonable. Hierl et al. (1997) also found a big difference between the high-temperature flowing afterglow and drift tube measurements (McFarland et al., 1973; Albritton et al., 1977) of the effective rate coefficient, $K_{2}$, for Reaction (2) as a result of the input of the reactions between the vibrationally excited $\mathrm{O}_{2}$ and $\mathrm{O}^{+}\left({ }^{4} \mathrm{~S}\right)$. These new results will be used in this paper.

The difference between the measurements of $K_{2}$ given by Hierl et al. (1997) and the scaled drift tube data is 
decreased with the decrease in $T_{n}$. As a result, like $\mathrm{N}_{2}(v)$, the effects of the vibrational excitation of $\mathrm{O}_{2}$ are expected to be more important during solar maximum than at solar minimum. In the first study of the $\mathrm{O}_{2}(v>0)$ effects on $\mathrm{NmF} 2$ given by Pavlov et al. (1998) for the 5-11 June 1991 storm, it was found that enhanced vibrational excitation of $\mathrm{O}_{2}$ leads up to a $40 \%$ decrease in the calculated $\mathrm{NmF} 2$ at solar maximum. In this paper we study the effects of $\mathrm{O}_{2}(v>0)$ on $\mathrm{NmF} 2$ for the 6-12 April 1990 geomagnetic storm which was at moderate solar-activity conditions (Buonsanto et al., 1992). We compare our results with previous modeling results given by Pavlov and Buonsanto (1997) for the April 1990 geomagnetic storm.

The new analytical formula for the dependence of $K_{2}$ on $T_{n}$ given by Hierl et al. (1997) is valid if the vibrational temperature of $\mathrm{O}_{2}, T_{v i b}=T_{n}$, and $T_{i}=T_{n}$. In an earlier study, Pavlov (1989) found that $T_{v i b}$ is close to $T_{n}$ and deviation from a Boltzmann distribution of $\mathrm{O}_{2}(v=1-4)$ was about a factor of $1.3-4$ at solar minimum and 1.2-2.4 at solar maximum during quiet conditions at the F2-region altitudes.

In this paper we will examine the effects of differences between $T_{v i b}$ and $T_{n}$ and Boltzmann and non-Boltzmann distributions of $\mathrm{O}_{2}(v)$ on the electron density during the April 1990 geomagnetic storm.

\section{Theoretical model}

The model used is an enhanced and updated version of the IZMIRAN model that we have steadily developed over the years (Pavlov, 1994a, 1997; Pavlov and Buonsanto, 1997). The chemistry, physics, and solution procedure have been described in detail by Pavlov (1994a, 1997) and hence only a brief description will be given here.

The IZMIRAN model is a one-dimensional model that uses a titled dipole approximation to the Earth's magnetic field and takes into account the offset between the geographic and geomagnetic axes. In the model, coupled time-dependent equations of continuity and energy balance, and diffusion equations for electrons, and $\mathrm{O}^{+}\left({ }^{4} \mathrm{~S}\right), \mathrm{H}^{+}$, and $\mathrm{He}^{+}$ions are solved along a centered-dipole magnetic field line for the concentrations, temperatures, and field-aligned diffusion velocities of ions and electrons from a base altitude $(160 \mathrm{~km})$ in the northern hemisphere through the plasmasphere to the same base altitude in the southern hemisphere. Electron heating due to photoelectrons is provided by a solution of the Boltzmann equation for photoelectron flux. We use the revised approach of Pavlov (1994a) described in Appendix A of this paper to calculate the rate of ionization by secondary photoelectrons. In the altitude range $120-700 \mathrm{~km}$ in the northern and southern hemispheres the IZMIRAN model solves time-dependent continuity equations for $\mathrm{O}^{+}\left({ }^{2} \mathrm{D}\right), \mathrm{O}^{+}\left({ }^{2} \mathrm{P}\right)$, $\mathrm{NO}^{+}, \mathrm{O}_{2}^{+}, \mathrm{N}_{2}^{+}$, and vibrationally excited molecular nitrogen, $\mathrm{N}_{2}(v)$, at the first five vibrational levels $v=$ $1-5$. Time-dependent continuity equations for $\mathrm{O}\left({ }^{1} \mathrm{D}\right)$ are solved in the region between 120 and $1500 \mathrm{~km}$ in altitude. The diffusion of ions and excited species are taken into account in continuity equations for $\mathrm{NO}^{+}, \mathrm{O}_{2}^{+}, \mathrm{O}\left({ }^{1} \mathrm{D}\right)$, and $\mathrm{N}_{2}(v)$, while densities of $\mathrm{O}^{+}\left({ }^{2} \mathrm{D}\right), \mathrm{O}^{+}\left({ }^{2} \mathrm{P}\right)$, and $\mathrm{N}_{2}^{+}$are obtained from local chemical equilibrium.

In the altitude range $120-700 \mathrm{~km}$ in the northern and southern hemispheres the updated IZMIRAN model solves time-dependent continuity equations for vibrationally excited molecular oxygen, $\mathrm{O}_{2}(v)$, at the first five vibrational levels $v=1-5$ and the time-dependent energy equation for the vibrational quanta of $\mathrm{O}_{2}(v)$ as described in Appendix B. An additional production of $\mathrm{O}^{+}\left({ }^{4} \mathrm{~S}\right), \mathrm{O}^{+}\left({ }^{2} \mathrm{D}\right)$, and $\mathrm{O}^{+}\left({ }^{2} \mathrm{P}\right)$ ions is obtained in the updated IZMIRAN model by inclusion of $\mathrm{O}^{+}\left({ }^{4} \mathrm{P}\right)$ and $\mathrm{O}^{+}\left({ }^{2} \mathrm{P}^{*}\right)$ ions. We believe that the $\mathrm{O}^{+}\left({ }^{4} \mathrm{P}\right)$ state decays promptly to $\mathrm{O}^{+}\left({ }^{4} \mathrm{~S}\right)$, while $\mathrm{O}^{+}\left({ }^{2} \mathrm{P}^{*}\right)$ ions decay to either $\mathrm{O}^{+}\left({ }^{2} \mathrm{D}\right)$ or $\mathrm{O}^{+}\left({ }^{2} \mathrm{P}\right)$ with a branching ratio of 2.6:1 for $\mathrm{O}^{+}\left({ }^{2} \mathrm{D}\right): \mathrm{O}^{+}\left({ }^{2} \mathrm{P}\right)$ (Kirby et al., 1979). The revised photoionization and photoabsorption cross sections are taken from Richards et al. (1994a); these authors did not publish the photoionization cross section for $\mathrm{He}$, and for these we have used values from Samson et al. (1994). The revised electron cooling rates by vibrational and rotational excitation of $\mathrm{O}_{2}$ and $\mathrm{N}_{2}$ given by Pavlov (1998a, b) are included in the updated IZMIRAN model.

The rate coefficient $K_{D}$, for quenching of $\mathrm{O}^{+}\left({ }^{2} \mathrm{D}\right)$ by atomic oxygen has not been measured in the laboratory. Widely diverging values of $10^{-10} \mathrm{~cm}^{3} \mathrm{~s}^{-1}$ (Oppenheimer et al., 1997; Fox and Dalgarno, 1985) and $5.10^{-12} \mathrm{~cm}^{3} \mathrm{~s}^{-1}$ (Abdou et al., 1984) have been proposed from comparison between measured and modeled $\left[\mathrm{N}_{2}^{+}\right]$. Previous work concerning the role played by $\mathrm{N}_{2}(v)$ in the formation of the F-region electron density and temperature during the period 6-12 April 1990 have assumed $K_{D}=10^{-10} \mathrm{~cm}^{3} \mathrm{~s}^{-1}$ (Pavlov and Buonsanto, 1997 ) and this rate coefficient is used in our paper.

The energy balance equations for ions of the IZMIRAN model take into account the perpendicular component, $E_{\perp}$, of the electric field with respect to the geomagnetic field, and the rate coefficients of such important ionospheric processes as the reactions of $\mathrm{O}^{+}\left({ }^{4} \mathrm{~S}\right)$ with $\mathrm{N}_{2}$ and $\mathrm{O}_{2}$ and $\mathrm{N}_{2}^{+}$with $\mathrm{O}_{2}$ depend on effective temperatures which are functions of the ion temperature, the neutral temperature and $E_{\perp}$ (Pavlov, 1997). The values of $E_{\perp}$ given by Buonsanto et al., (1992) are used as input parameters for our theoretical model.

The three key inputs to the IZMIRAN models are the concentrations and temperatures of the neutral constituents, the solar EUV fluxes, and the plasma drift velocity. To simulate magnetic storm effects on the neutral atmosphere the MSIS-86 model (Hedin, 1987) was run using 3-h Ap indices. The IZMIRAN model uses the solar EUV fluxes from EUV94X model (Tobiska, 1993, 1994) or the EUVAC model (Richards et al., 1994a). For the period 6-9 April 1990 the EUV94X model produces the largest electron densities increasing $\mathrm{NmF} 2$ by about $10-40 \%$ compared to the EUVAC model, and the EUV94X model results agree better with the observations in comparison to using the 
EUVAC model (Pavlov and Buonsanto, 1997). Therefore the EUV94X model is used in this paper. At night the IZMIRAN model includes ionization by scattered solar fluxes.

In the northern hemisphere, instead of calculating thermospheric wind components by solving the momentum equations, the IZMIRAN model calculates an equivalent neutral wind from the hmF2 measurements using the modified method of Richards (1991) described by Pavlov and Buonsanto (1997). The momentum equations for the horizontal components of the thermospheric wind are calculated in the altitude range 120 $700 \mathrm{~km}$ of the southern hemisphere where we do not have the observed hmF2, and the method developed by Pavlov (1996) to calculate an equivalent plasma drift velocity is used.

Burnside et al. (1987) recommended the use of the Banks (1966) value of the $\mathrm{O}^{+}-\mathrm{O}$ collision frequency increased by a factor $F=1.7$. The study of Buonsanto et al. (1997) involving more sophisticated analysis of observational data has led to $F \sim 1.3$. As a result, the $\mathrm{O}^{+}-\mathrm{O}$ collision frequency formula given by Pesnell et al. (1993) which is fully consistent with the conclusions of Buonsanto et al. (1997) is used in the updated IZMIRAN model.

The distribution of ionization in the topside ionosphere and plasmasphere is strongly controlled by the geomagnetic field, and therefore the IZMIRAN model calculations may be considered valid up to $L=6$, where the dipole approximation of the geomagnetic field is reasonably accurate. The IZMIRAN model describes only the transfer of plasma along a centered-dipole magnetic field line and does not take into account the perpendicular divergence contribution in the ion equations of continuity. As a result, the model cannot give a correct description of the ionosphere between -20 and 20 degrees magnetic latitude, as that would require taking into account the exchange of ions and electrons between magnetic flux tubes because of the action of electromagnetic drift due to electric fields.

\section{Updated loss rate of $\mathrm{O}^{+}\left({ }^{4} \mathrm{~S}\right)$ ions}

The loss rate of $\mathrm{O}^{+}\left({ }^{4} \mathrm{~S}\right)$ ions

$L=K_{1}\left[\mathrm{~N}_{2}\right]+K_{2}\left[\mathrm{O}_{2}\right]$,

The effective rate coefficients of Reactions (1) and (2) are determined as

$$
\begin{aligned}
& K_{1}=\sum_{v=0}^{\infty}\left[\mathrm{N}_{2}(v)\right] K_{1 v} /\left[\mathrm{N}_{2}\right], \\
& K_{2}=\sum_{v=0}^{\infty}\left[\mathrm{O}_{2}(v)\right] K_{2 v} /\left[\mathrm{O}_{2}\right],
\end{aligned}
$$

where $K_{1 v}$ is the recombination rate coefficient of $\mathrm{O}^{+}\left({ }^{4} \mathrm{~S}\right)$ ions with $\mathrm{N}_{2}(v), K_{2 v}$ is the recombination rate coefficient of $\mathrm{O}^{+}\left({ }^{4} \mathrm{~S}\right)$ ions with $\mathrm{O}_{2}(v),\left[\mathrm{N}_{2}\right]=\sum_{v=0}^{\infty}\left[\mathrm{N}_{2}(v)\right],\left[\mathrm{O}_{2}\right]=$ $\sum_{v=0}^{\infty}\left[\mathrm{O}_{2}(v)\right] ;\left[\mathrm{N}_{2}(v)\right]$ and $\left[\mathrm{O}_{2}(v)\right]$ are the number densities of $\mathrm{N}_{2}$ and $\mathrm{O}_{2}$ at the $v$-th vibrational level, the sum of the vibrationally unexcited and excited molecular nitro- gen and oxygen concentrations $\left[\mathrm{N}_{2}\right]$ and $\left[\mathrm{O}_{2}\right]$ are calculated from the MSIS model (Hedin, 1987).

McFarland et al. (1973) and Albritton et al. (1977) measured the effective rate coefficients, Eqs. (4) and (5) of $\mathrm{O}^{+}\left({ }^{4} \mathrm{~S}\right)$ ions with $\mathrm{N}_{2}$ and $\mathrm{O}_{2}$ in flow-drift tubes for $T_{n}=T_{v}=T_{v i b}=300 \mathrm{~K}$ and $300 \leq T_{i} \leq 6000 \mathrm{~K}$. The number densities of $\mathrm{N}_{2}(v>0)$ and $\overline{\mathrm{O}}_{2}(v>0)$ are neglected for $T_{v}=300 \mathrm{~K}$ in comparison with the number density of unexcited $\mathrm{N}_{2}$, and as a result, we conclude that $K_{1}$ is very close to the rate coefficient, $K_{10}$, of $\mathrm{O}^{+}\left({ }^{4} \mathrm{~S}\right)$ ions with $\mathrm{N}_{2}(v=0)$ (Pavlov, 1986; Richards and Torr, 1986) and $K_{2}$ is very close to the rate coefficient, $K_{20}$, of $\mathrm{O}^{+}\left({ }^{4} \mathrm{~S}\right)$ ions with $\mathrm{O}_{2}(v=0)$.

Helium-buffered $K_{1}$ and $K_{2}$ from Albritton et al. (1977) differ from argon-buffered $K_{1}$ and $K_{2}$ given by McFarland et al. (1973) as a result of a non-Maxwellian speed distribution of $\mathrm{O}^{+}\left({ }^{4} \mathrm{~S}\right)$ ions due to very strong electric fields in these flow-drift tube studies and dependence of this speed distribution of $\mathrm{O}^{+}\left({ }^{4} \mathrm{~S}\right)$ ions on the kind of buffered gas in the flow-drift tube (Albritton et al. 1977; Viehland and Mason, 1977; St.Maurice and Torr, 1978). The non-thermal rate coefficient measurements of McFarland et al. (1973) and Albritton et al. (1977) were used by Viehland and Mason (1977) and St.-Maurice and Torr (1978) to calculate the thermal rate coefficient of $\mathrm{O}^{+}\left({ }^{4} \mathrm{~S}\right)$ ions with $\mathrm{N}_{2}$ and $\mathrm{O}_{2}$ for a Maxwellian speed distribution of $\mathrm{O}^{+}\left({ }^{4} \mathrm{~S}\right)$ ions which is needed for ionospheric calculations. It was found by Viehland and Mason (1977) and St.-Maurice and Torr (1978) that these thermal rate coefficients depend on $T_{n}$ and $T_{i}$ only by means of an effective temperature

$$
\begin{aligned}
T= & \left(m_{i} T_{n}+m_{n} T_{i}\right)\left(m_{i}+m_{n}\right)^{-1} \\
& +m_{i} m_{n} V_{d}^{2}\left(m_{i}+m_{n}\right)^{-1}(3 k)^{-1},
\end{aligned}
$$

where $k$ is Boltzmann's constant, $V_{d}$ is a relative drift velocity between ions and molecules, $m_{i}$ and $m_{n}$ denote masses of ions and neutral molecules.

St.-Maurice and Torr (1978) presented the analytical formula for the dependence of the drift tube data thermal rate coefficient of $\mathrm{O}^{+}\left({ }^{4} \mathrm{~S}\right)$ ions with $\mathrm{N}_{2}(v=0)$ on the effective temperature, and this approximation is used in the IZMIRAN model:

$$
\begin{aligned}
K_{10}= & 1.533 \cdot 10^{-12}-5.92 \cdot 10^{-13}(T / 300) \\
& +8.60 \cdot 10^{-14}(T / 300)^{2} \text { for } 300 \leq T \leq 1700 \mathrm{~K}, \\
K_{10}= & 2.73 \cdot 10^{-12}-1.155 \cdot 10^{-12}(T / 300) \\
& +1.483 \cdot 10^{-13}(T / 300)^{2} \text { for } 1700<T<6000 \mathrm{~K} .
\end{aligned}
$$

The high-temperature flowing afterglow measurements of the recombination rate coefficient of $\mathrm{O}^{+}\left({ }^{4} \mathrm{~S}\right)$ ions with $\mathrm{O}_{2}$ given by Hierl et al. (1997) are lower than the flow-drift tube data from McFarland et al. (1973) and Albritton et al. (1977). Hierl et al. (1997) scaled the drift tube data by a factor of 0.8 within the uncertainty of either data set so that the flowing afterglow measurements of $K_{2}$ and the drift tube data coincide at the lowest neutral temperature studies, namely, $400 \mathrm{~K}$. As a 
result, the IZMIRAN model was updated by the use of the new temperature dependence of the drift tube data thermal rate coefficient of $\mathrm{O}^{+}\left({ }^{4} \mathrm{~S}\right)$ ions with $\mathrm{O}_{2}(v=0)$ on an effective temperature given by Hierl et al. (1997) as

$K_{20}=1.6 \cdot 10^{-11}(300 / T)^{0.52}+5.5 \cdot 10^{-11} \exp (-6835 / T)$,

where the units of $K_{20}$ are $\mathrm{cm}^{3} \mathrm{~s}^{-1}$.

The latest version of the IZMIRAN model, given in Pavlov (1997), included the option to use three sets of models of the rate coefficients of $\mathrm{O}^{+}\left({ }^{4} \mathrm{~S}\right)$ ions with $\mathrm{N}_{2}(v>0)$. The first uses the temperature dependence of $K_{1 v}(T)$ from the Van Zandt and O'Malley (1973) theory. The second model uses the recombination rate coefficients of $\mathrm{O}^{+}\left({ }^{4} \mathrm{~S}\right)$ ions with $\mathrm{N}_{2}(v>0)$ measured by Schmeltekopf et al. (1968) for $T_{n}=T_{i}=300 \mathrm{~K}$, and it is assumed that the temperature dependence of $K_{1 v}(T)$ is the same as the temperature dependence of $K_{10}(T)$ :

$$
\begin{aligned}
K_{11}(T) & =K_{10}(T), K_{12}(T)=38 K_{10}(T), K_{13}(T) \\
& =85 K_{10}(T), K_{14}(T)=220 K_{10}(T), K_{15}(T) \\
& =270 K_{10}(T) .
\end{aligned}
$$

The third one assumes no temperature dependence of these reaction rate coefficients, i.e., they are the same as measured by Schmeltekopf et al. (1968) for $T_{v}=T_{n}=$ $T_{i} \equiv T_{0}=300 \mathrm{~K}$ :

$$
\begin{aligned}
& K_{11}(T)=K_{10}\left(T_{0}\right), K_{12}(T)=38 K_{10}\left(T_{0}\right), \\
& K_{13}(T)=85 K_{10}\left(T_{0}\right), K_{14}(T)=220 K_{10}\left(T_{0}\right), \\
& K_{15}(T)=270 K_{10}\left(T_{0}\right) .
\end{aligned}
$$

The effective rate coefficients for the reaction $\mathrm{O}^{+}\left({ }^{4} \mathrm{~S}\right)$ with $\mathrm{N}_{2}$ have been measured for the first time over the temperature range $300-1600 \mathrm{~K}$ for $T=T_{n}=T_{i}=T_{v}$ (Hierl et al., 1997) and these results confirm the observations of Schmeltekopf et al. (1968). Figure 1 shows the temperature dependence of the effective rate coefficient in Eq. (4) given by Hierl et al. (1997) (crosses), the Van Zandt and O'Malley (1973) theory (dashed line), the assumptions of Eqs. (9) (solid line) and (10) (dotted line). It is seen that the Van Zandt and O'Malley (1973) theory or the assumption of Eq. (10) do not agree with the recent measurements of $K_{1}$ gigen by Hierl et al. (1997) and Eq. (9) of similar translation dependencies for different states is reasonable. As a result of the new measurements of $K_{1}$ given by Hierl et al. (1997), the IZMIRAN model was updated by the use of the single temperature dependence of Eq. (9).

The heated drift tube measurements of the recombination rate coefficient of $\mathrm{O}^{+}\left({ }^{4} \mathrm{~S}\right)$ ions with $\mathrm{O}_{2}$ given by Chen et al. (1978) are systematically lower than the flow-drift tube measurements, $\gamma_{E}$, of this rate coefficient (Albritton et al., 1977). In an attempt to reconcile these two sets of measurements, the IZMIRAN model used the analytical formula given by Pavlov (1997) as $K_{2}(T)=\gamma_{E}(T) \exp \left(-8.53 \cdot 10^{-4} T_{n}+0.315\right)$. Figure 2 shows the new measurements of $K_{2}(T)$ in a hightemperature flowing afterglow over the temperature range $T=300-1800 \mathrm{~K}\left(T=T_{n}=T_{i}=T_{v i b}\right)$ given by

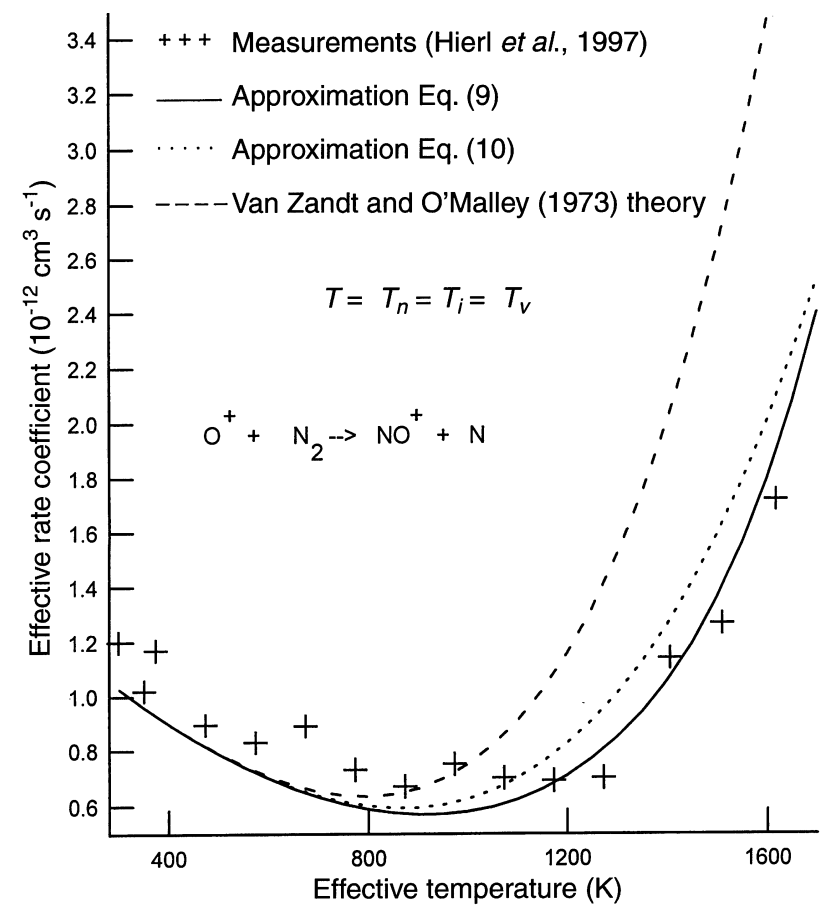

Fig. 1. Effective rate coefficients for the reaction of $\mathrm{O}^{+}\left({ }^{4} \mathrm{~S}\right)$ with $\mathrm{N}_{2}$ as a function of a temperature from the measurements given by Hierl et al. (1997) (crosses), the Van Zandt and O'Malley (1973) theory (dashed line) of $K_{1 v}(v>0)$, the assumptions in Eqs. (9) (solid line) and (10) (dotted line) for $T=T_{v}=T_{n}=T_{i}$

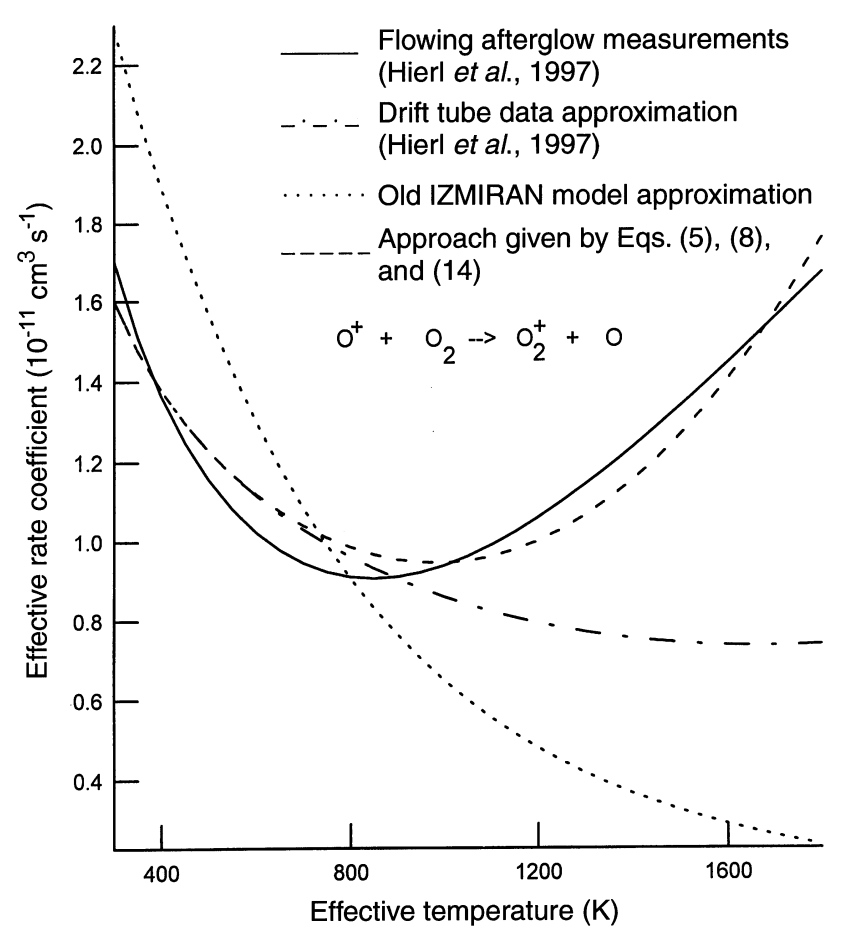

Fig. 2. Effective rate coefficients for the reaction of $\mathrm{O}^{+}\left({ }^{4} \mathrm{~S}\right)$ with $\mathrm{O}_{2}$ as a function of a temperature from a high-temperature flowing afterglow (Hierl et al., 1997) (solid line), drift tube data of Albritton et al. (1977) scaled by a factor of 0.8 (Hierl et al., 1997) (dashed-dotted line), the old IZMIRAN model approximation given by Pavlov (1997) (dotted line), and Eqs. (5), (8), and (14) (dashed line) 
Hierl et al. (1997) (solid line), drift tube data of Albritton et al. (1977) for $T=T_{i}$ and $T_{n}=T_{v i b}=300 \mathrm{~K}$ revised by Hierl et al. (1997) (dashed-dotted line), and the old IZMIRAN model approximation (dotted line). The rate coefficient of $\mathrm{O}^{+}\left({ }^{4} \mathrm{~S}\right)$ ions with $\mathrm{O}_{2}$ measured by Hierl et al. (1997) decreases with increasing temperature up to $800-$ $1100 \mathrm{~K}$, while the drift tube of McFarland et al. (1973) and Albritton et al. (1977) decreases to about $1500-1600 \mathrm{~K}$. At low temperatures, the rate constant taken in the drift tube study is larger than those found from the Hierl et al. (1997) measurements. The value of $K_{2}$ given by Hierl et al. (1997) increases with increasing temperature for $T>800-1100 \mathrm{~K}$ as a result of the reactions between the vibrationally excited $\mathrm{O}_{2}$ and $\mathrm{O}^{+}\left({ }^{4} \mathrm{~S}\right)$ (Hierl et al., 1997).

The new dependence of $K_{2}$ on $T_{n}$ is given by Hierl et al. (1997) for $T_{n}=T_{i}=T_{v i b}$ in the temperature range $300-1600 \mathrm{~K}$ as

$$
\begin{aligned}
K_{2}= & 1.7 \cdot 10^{-11}\left(300 / T_{n}\right)^{0.77} \\
& +8.54 \cdot 10^{-11} \exp \left(-3467 / T_{n}\right),
\end{aligned}
$$

where the units of $K_{2}$ are $\mathrm{cm}^{3} \mathrm{~s}^{-1}$. These flowing afterglow measurements of $K_{2}$ can be used to invert the data to give the rate coefficients for the various vibrational levels of $\mathrm{O}_{2}(v>0)$ for the model of the Boltzmann distribution of vibrationally excited molecular oxygen

$\left[\mathrm{O}_{2}(v)\right]_{B}=\left[\mathrm{O}_{2}(0)\right] \exp \left(-v E_{1} T_{v i b}^{-1}\right)$,

where $E_{1}=2239 \mathrm{~K}$ is the energy of the first level of $\mathrm{O}_{2}$ given by Radzig and Smirnov (1980),

$$
\left[\mathrm{O}_{2}(0)\right]=\left[O_{2}\right]\left\{1-\exp \left(-E_{1} T_{v i b}^{-1}\right)\right\} \text {. }
$$

Solving the system of Eqs. (5), (8), and (11) we can calculate $K_{2 v}(v>0)$ as

$$
\begin{aligned}
K_{21}(T) & =K_{20}(T), K_{22}(T)=5 K_{20}(T), K_{23}(T)=K_{24}(T) \\
& =K_{25}(T)=50 K_{20}(T) .
\end{aligned}
$$

Figure 2 gives the comparison of $K_{2}$ from flowing afterglow measurements given by Hierl et al. (1997) (solid line) with $K_{2}$ calculated from Eqs. (5), (8), and (14) (dashed line). We can see that the use of our new approach given by Eqs. (5), (8), and (14) describes the measured $K_{2}$ to sufficient accuracy with maximum error in $10 \%$. The updated IZMIRAN model uses this new approach taking into account differences between $T_{v i b}$, $T_{n}$, and $T_{i}$.

\section{Undisturbed period and storms of 6-12 April 1990}

The undisturbed conditions of 6-8 April 1990 and the 912 April 1990 magnetic storms were periods of moderate solar activity when the 10.7 solar flux varied between 146 and 169 and geomagnetic index Ap was between 6 and 124. During the April 1990 period two geomagnetic storms took place with sudden commencement times near 08:42 UT on 9 April and 03:25 UT on 12 April. The measured electron densities and the perpendicular electric fields (with respect to the magnetic field), $E_{\perp}$, used in this paper were taken by the incoherent-scatter radar at Millstone Hill, Massachusetts (Buonsanto et al., 1992).

Figure 3 is a plot of the measured hmF2 and NmF2 for the period 6-12 April 1990 and the model results with effects of $E_{\perp}$ included in calculations of ion temperatures (Pavlov and Buonsanto, 1997; Pavlov, 1997) and rate coefficients Eqs. (4) and (5) of vibrationally excited $\mathrm{O}_{2}$ and $\mathrm{N}_{2}$ included in the calculated $\mathrm{O}^{+}\left({ }^{4} \mathrm{~S}\right)$ recombination rate of Eq. (3) which will be discussed later. We can see that there are only negative phases in the measured NmF2 (crosses at bottom panel) compared to the undisturbed period of 6-7 April. The most notable feature of this period is the disappearance of the F2 peak on 10 April, when the peak height of the electron density maximum dropped to $180 \mathrm{~km}$.

\subsection{Anomalous electron density events on 10 April}

Figure 3 shows that extremely low NmF2 and hmF2 (rather, it was the F1 peak) were observed between 9:30 and 14:30 LT on 10 April. It is one of the most striking features of the mid-latitude ionospheric $F$ region (the "G condition") seen on ionograms, when the critical frequency of the F2 layer is lower than the critical frequency of the F1 layer. The $G$ condition could be explained either by decreases in the densities of $\mathrm{O}^{+}\left({ }^{4} \mathrm{~S}\right)$, or by increases in the densities of the molecular ions. These species concentrations can be changed in several ways. Pavlov and Buonsanto (1997) calculations indicate that the electron density decreases if the electric field strength increases due to the increased rates of the reactions $\mathrm{O}^{+}\left({ }^{4} \mathrm{~S}\right)$ with $\mathrm{N}_{2}$ and $\mathrm{O}_{2}$ relative to the zero electric field result while the $\mathrm{NO}^{+}$and $\mathrm{O}_{2}^{+}$densities are increased. For $E_{\perp} \sim 90-100 \mathrm{mV} \mathrm{m}^{-1}$, the decrease in $\mathrm{O}^{+}\left({ }^{4} \mathrm{~S}\right)$ ion density is sufficient to cause the density of molecular ions to be greater than the $\mathrm{O}^{+}\left({ }^{4} \mathrm{~S}\right)$ ion density. As a result, the usual F2-region peak created by $\mathrm{O}^{+}\left({ }^{4} \mathrm{~S}\right)$ ions vanishes, the new $\mathrm{F} 2$ region peak (rather, it is the F1 peak) due to molecular ions results and the extremely low observed NmF2 and hmF2 can be explained. However, $E_{\perp} \sim 90-100 \mathrm{mV} \mathrm{m}^{-1}$ were not observed between 9:30 and 14:30 LT on 10 April (Buonsanto et al., 1992) and therefore Pavlov and Buonsanto (1997) were unable to account for the observed $\mathrm{NmF} 2$ and hmF2.

The disagreement in $\mathrm{NmF} 2$ and hmF2 between the model and the data during the $\mathrm{G}$ condition may be due to discrepances in the neutral densities. To study the reaction of the neutral densities on the storm we have calculated the neutral densities for some hypothetical undisturbed conditions with the same solar and time conditions as during the studied conditions. At $300 \mathrm{~km}$ between 0:00 and 14:30 LT on 10 April the O density was from $1 \%$ to $13 \%$ higher than during these hypothetical undisturbed conditions, while the $\mathrm{N}_{2}$ density 


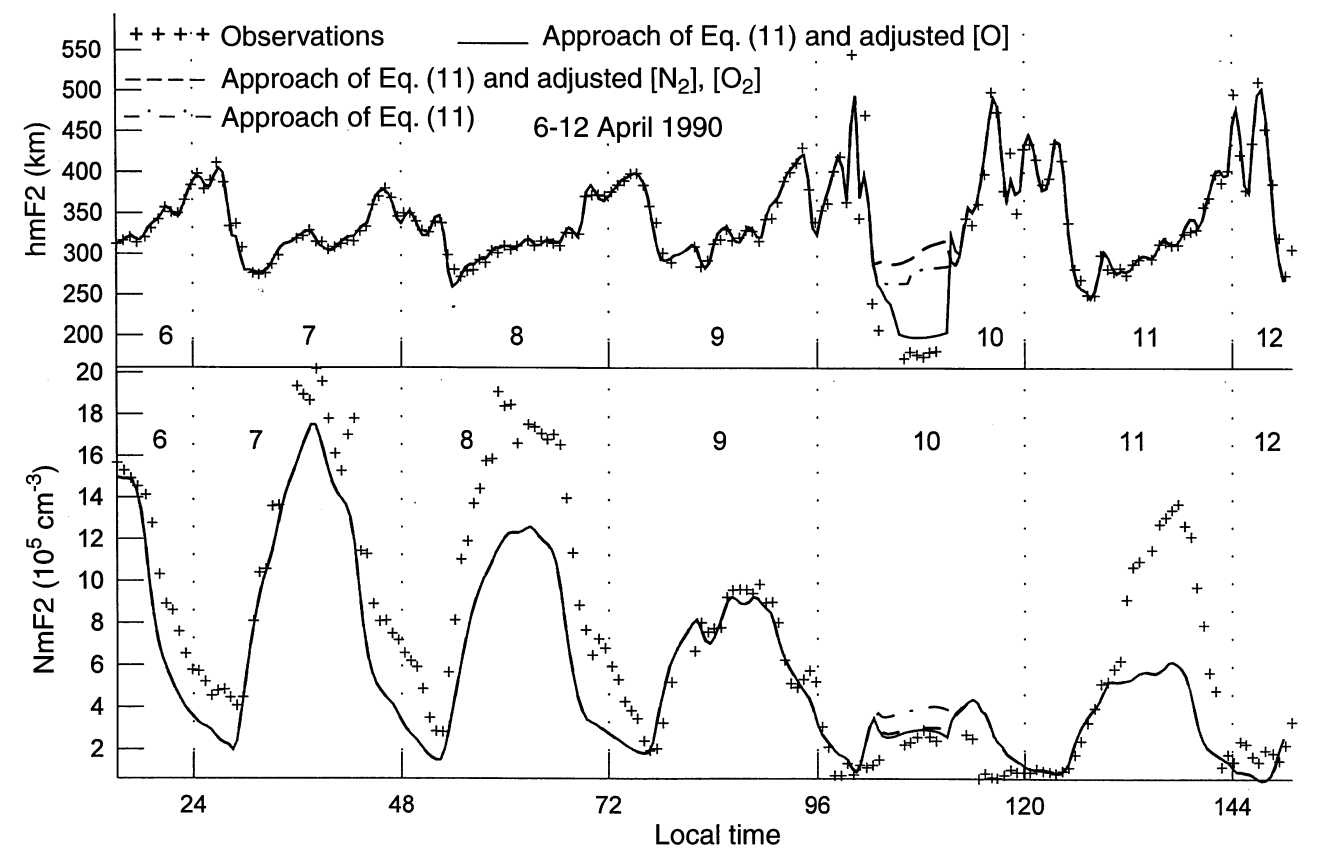

Fig. 3. Observed (crosses) and calculated F2 peak parameters above Millstone Hill for the magnetically quiet and disturbed period 6-12 April 1990. Top: hmF2, and bottom: NmF2. The model results were obtained using the approach of Eq. (11). The dashed-dotted lines show results from the IZMIRAN model using the unadjusted MSIS-86

increased by a factor of 1.6-2.4 and the $\mathrm{O}_{2}$ density increased by a factor of 2.0-4.1 over the hypothetical undisturbed $\left[\mathrm{N}_{2}\right]$ and $\left[\mathrm{O}_{2}\right]$. This type of behavior of $[\mathrm{O}]$, $\left[\mathrm{N}_{2}\right]$, and $\left[\mathrm{O}_{2}\right]$ is not unusual during storms. However, during some storms the measured $\mathrm{O}$ density at $300 \mathrm{~km}$ remains steady or decreases during the negative phases of ionospheric storms (Prolss, 1980). As far as the author knows, there is no other published evidence that during storms the values of $[\mathrm{O}],\left[\mathrm{N}_{2}\right]$, and $\left[\mathrm{O}_{2}\right]$ are higher or lower compared to the MSIS-86 values. Nevertheless, several limitations of the semi-empirical model of the neutral atmosphere MSIS-86 are apparent. As a result of a limited amount of measurements of number densities, not all geophysical conditions are well represented in this model. MSIS-86 neutral densities were primarily obtained using measurements taken by rockets and satellites. The AE-C, AE-D, and AE-E satellites had orbits of approximately $3 \mathrm{~h}$ and with this time resolution between observations short-time changes in the neutral composition cannot be observable in the neutral density data. The 3-h Ap indices which are used in the MSIS-86 model are poorly correlated with the temporal variations of very large density perturbations in the thermosphere (Nisbet et al., 1983).

Let us evaluate the changes that would be needed in the MSIS-86 model to produce the observed G condition in the ionosphere. To study this anomaly in hmF2 we used the approach of Eq. (11) for $K_{2}$ and three neutral atmosphere models in our calculations. Dasheddotted lines in Fig. 3 show the results obtained using the standard MSIS-86 model. Figure 3 also gives the calculated NmF2 and hmF2 using two adjusted MSIS86 models for all altitudes between 07:00 and 15:00 LT neutral atmosphere model. Solid and dashed lines show effects of adjustments to the MSIS-86 model between 07:00 and 15:00 LT on 10 April at all altitudes. Solid lines shows results when the MSIS-86 model [O] was decreased by a factor 1.8. Dashed lines show results when the MSIS-86 model $\left[\mathrm{N}_{2}\right]$ and $\left[\mathrm{O}_{2}\right]$ were increased by a factor of 2

on 10 April. Solid lines show results when the atomic oxygen density was decreased by a factor of 1.8 , and dashed lines show results when the $\mathrm{N}_{2}$ and $\mathrm{O}_{2}$ densities were increased by a factor of 2 at all altitudes. No adjustments were made to the $[\mathrm{O}],\left[\mathrm{N}_{2}\right]$, and $\left[\mathrm{O}_{2}\right]$ values at any other times. This decrease in neutral atomic oxygen density results in a decrease in the production of $\mathrm{O}^{+}$by photoionization and photoelectron impact while this increase in $\left[\mathrm{N}_{2}\right]$ and $\left[\mathrm{O}_{2}\right]$ results in an increase in the $\mathrm{O}^{+}$recombination rate, simultaneously decreasing $\left[\mathrm{O}^{+}\right]$ and increasing $\left[\mathrm{NO}^{+}\right]$and $\left[\mathrm{O}_{2}^{+}\right]$. The best agreement between the hmF2 measurements and the model results is obtained when the MSIS-86 atomic oxygen adjustment is used. There is a large disagreement between the measured and modeled hmF2 when the original MSIS86 model or the MSIS- 86 model with the adjusted $\mathrm{N}_{2}$ and $\mathrm{O}_{2}$ densities is used in the calculations of $N_{e}$. The [O] adjustment is sufficient to reproduce with good accuracy the observed hmF2 and NmF2 on 10 April.

\subsection{Non-Boltzmann distribution of $\mathrm{O}_{2}(v)$ and vibrational temperatures of $\mathrm{O}_{2}$ and $\mathrm{N}_{2}$}

The difference between the approach of Eq. (11) and the method given by Eqs. (5), (8), and (14) for $K_{2}$ can give effects on the electron density. To study these effects of differences between $T_{v i b}$ and $T_{n}$ and Boltzmann [see Eq. (12)] and non-Boltzmann distributions of $\mathrm{O}_{2}(v)$ on the electron density during the April 1990 geomagnetic storm the IZMIRAN model solves Eqs. (B1)-(B2) in the altitude range $120-700 \mathrm{~km}$ in the northern and southern hemispheres as described in Appendix B. 


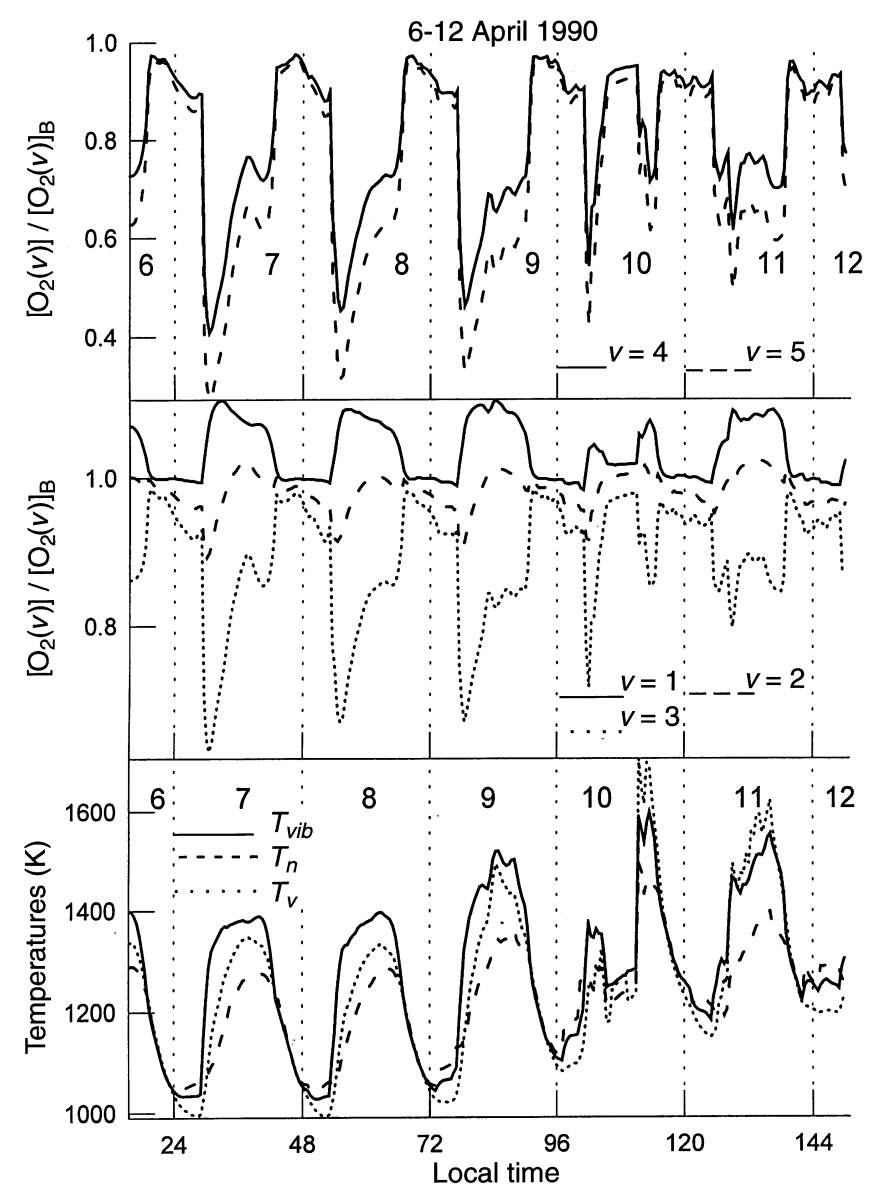

Fig. 4. The time variations of the vibrational temperatures of $\left[\mathrm{O}_{2}\right]$ and $\left[\mathrm{N}_{2}\right]$, the neutral temperature (bottom panel), and populations of the first five vibrational levels of $\mathrm{O}_{2}(v=1,2$, and 3 at the middle panel and $v=4$ and 5 at the top panel) in comparison with the Boltzmann distribution of Eq. (12) during the 6-12 April period at the F2 peak altitude. The solid lines show the modeled $T_{v i b},\left[\mathrm{O}_{2}(1)\right] /\left[\mathrm{O}_{2}(1)\right]_{B}$, and $\left[\mathrm{O}_{2}(4)\right] /\left[\mathrm{O}_{2}(4)\right]_{B}$, the dashed lines show the modeled $T_{n},\left[\mathrm{O}_{2}(2)\right] /$ $\left[\mathrm{O}_{2}(2)\right]_{B}$, and $\left[\mathrm{O}_{2}(5)\right] /\left[\mathrm{O}_{2}(5)\right]_{B}$, and the dotted lines show the modeled $T_{v}$, and $\left[\mathrm{O}_{2}(3)\right] /\left[\mathrm{O}_{2}(3)\right]_{B}$. The approach given by Eqs. (5), (8), and (14) for $K_{2}$ was used in the model of the ionosphere and plasmasphere

The results of calculating $\left[\mathrm{O}_{2}(v)\right] /\left[\mathrm{O}_{2}(v)\right]_{B}, T_{v i b}, T_{v}$, and $T_{n}$ at hmF2 are presented in Fig. 4 . Table 1 shows the limits of changing for $\left[\mathrm{O}_{2}(v)\right] /\left[\mathrm{O}_{2}(v)\right]_{B}$ at $\mathrm{hmF} 2$. The present study suggests that the deviations $\left[\mathrm{O}_{2}(v)\right]$ from the Boltzmann distribution of Eq. (12) are not significant. For second, third, fourth and fifth vibrational levels of $\mathrm{O}_{2}$ the ratios $\left[\mathrm{O}_{2}(v)\right] /\left[\mathrm{O}_{2}(v)\right]_{B}$ have their minimum values during the period 6.30-7.30 LT. From the diurnal variations of the calculated vibrational (solid line) and neutral (dashed line) temperatures shown in

Table 1. The deviations of $\mathrm{O}_{2}(v)$ from the Boltzmann distribution at the F2 peak altitude

\begin{tabular}{ll}
\hline$\left[\mathrm{O}_{2}(1)\right] /\left[\mathrm{O}_{2}(1)\right]_{\mathrm{B}}$ & $0.98-1.11$ \\
{$\left[\mathrm{O}_{2}(2)\right] /\left[\mathrm{O}_{2}(2)\right]_{\mathrm{B}}$} & $0.89-1.02$ \\
{$\left[\mathrm{O}_{2}(3)\right] /\left[\mathrm{O}_{2}(3)\right]_{\mathrm{B}}$} & $0.63-0.99$ \\
{$\left[\mathrm{O}_{2}(4)\right] /\left[\mathrm{O}_{2}(4)\right]_{\mathrm{B}}$} & $0.41-0.97$ \\
{$\left[\mathrm{O}_{2}(5)\right] /\left[\mathrm{O}_{2}(5)\right]_{\mathrm{B}}$} & $0.27-0.97$ \\
\hline
\end{tabular}

Fig. 4, it follows that $T_{v i b}<T_{n}$ and $T_{v}<T_{n}$ are realized in the atmosphere for the nighttime periods where the production frequencies of $\mathrm{O}_{2}(v)$ and $\mathrm{N}_{2}(v)$ are low. This means that for these periods the populations of $\mathrm{O}_{2}(v)$ or $\mathrm{N}_{2}(v)$ are less than the populations for a Boltzmann distribution with temperature $T_{n}$. The calculations showed that during the quiet period 6-8 April the vibrational temperatures of $\mathrm{O}_{2}(v)$ and $\mathrm{N}_{2}(v)$ are less than during the magnetic storm period 9-12 April. During the daytime $T_{v i b}$ and $T_{v}$ are larger than $T_{n}$ due to the enhanced thermal excitation of $\mathrm{O}_{2}$ and $\mathrm{N}_{2}$ as a result of high thermal electron temperatures at F2-region altitudes. The differences $-78 \leq T_{v i b}-T_{n} \leq 230 \mathrm{~K}$ and $-148 \leq T_{v}-T_{n} \leq 246 \mathrm{~K}$. On 6-12 April the value of the vibrational temperature was not more than $1600 \mathrm{~K}$ for $\mathrm{O}_{2}$ and $1710 \mathrm{~K}$ for $\mathrm{N}_{2}$.

The comparison between the modeled densities using the simple approach of Eq. (11) with $T_{v i b}=T_{n}=T_{i}$ and the rigorous method given by Eqs. (5), (8), and (14) with the non-Boltzmann vibrational distribution of $\mathrm{O}_{2}$ and the difference between $T_{n}$ and $T_{i}$ was carried out. We found that the use of the rigorous method based on Eqs. (5), (8), and (14) leads to the increase up to about $3 \%$ or the decrease up to about $4 \%$ of the calculated $\mathrm{NmF} 2$ in comparison with $\mathrm{NmF} 2$ calculated by using the simple approach of Eq. (11). So, the use of Eq. (11) for $K_{2}$ gives NmF2 to sufficient accuracy during daytime and nighttime quiet and disturbed periods.

\subsection{Effects of vibrational excited oxygen and nitrogen on electron density}

As a result of the new measurements of the rate coefficients for the reaction $\mathrm{O}^{+}\left({ }^{4} \mathrm{~S}\right)$ with $\mathrm{N}_{2}$ and $\mathrm{O}_{2}$ given by Hierl et al. (1997), there are no uncertainties in the vibrational and temperature dependencies of the $\mathrm{O}^{+}\left({ }^{4} \mathrm{~S}\right)+\mathrm{N}_{2}(v>0)$ and $\mathrm{O}^{+}\left({ }^{4} \mathrm{~S}\right)+\mathrm{O}_{2}(v>) 0$ reaction rates and a comparison between the measured and modeled $\mathrm{NmF} 2$ with and without effects of $\mathrm{N}_{2}(v>0)$ and $\mathrm{O}_{2}(v>0)$ cannot be any argument in favor of or against the use of $\mathrm{N}_{2}(v>0)$ and $\mathrm{O}_{2}(v>0)$ in ionospheric models. The inclusion or exclusion of $\mathrm{N}_{2}(v>0)$ and $\mathrm{O}_{2}(v>0)$ can only illustrate the role of these species in the ionosphere.

Figure 5 shows the role of vibrationally excited $\mathrm{O}_{2}$ and $\mathrm{N}_{2}$ in the ionosphere during the undisturbed and geomagnetic storm period of 6-12 April 1990. The top panel shows the observed and the modeled hmF2, while the bottom panel gives the observed and modeled NmF2. The solid line shows model results when vibrationally excited $\mathrm{O}_{2}$ and $\mathrm{N}_{2}$ are included in calculations of the $\mathrm{O}^{+}\left({ }^{4} \mathrm{~S}\right)$ loss rate as given by Eqs. (3)-(5). The dashed lines show model results when $\mathrm{O}_{2}(v>0)$ is not included and $\mathrm{N}_{2}(v>0)$ is included in calculations of the $\mathrm{O}^{+}\left({ }^{4} \mathrm{~S}\right)$ loss rate

$$
L=K_{1}\left[\mathrm{~N}_{2}\right]+K_{20}\left[\mathrm{O}_{2}(v=0)\right],
$$

where $K_{1}$ and $K_{20}$ are given by Eqs. (4) and (8).

The solid and dashed-dotted lines in Fig. 5 show that the increase in the $\mathrm{O}^{+}+\mathrm{N}_{2}$ loss rate due to vibration- 
ally excited $\mathrm{O}_{2}$ produces $8-46 \%$ reductions in $\mathrm{NmF} 2$. The dashed lines of Fig. 5 are model results when the vibrational excited nitrogen and oxygen are not included in the calculations of the loss rate the $\mathrm{O}^{+}\left({ }^{4} \mathrm{~S}\right)$ ions:

$L=K_{10}\left[\mathrm{~N}_{2}(v=0)\right]+K_{20}\left[\mathrm{O}_{2}(v=0)\right]$.

From Fig. 5 it follows that there is a large increase in the modeled NmF2 without vibrationally excited $\mathrm{O}_{2}$ and $\mathrm{N}_{2}$. The comparison of dashed-dotted and dashed lines shows that the increase in the $\mathrm{O}^{+}+\mathrm{N}_{2}$ rate factor due to the vibrationally excited nitrogen produces the 5$36 \%$ decrease in the calculated daytime peak density. The effects of vibrationally excited $\mathrm{O}_{2}$ and $\mathrm{N}_{2}$ on $N_{e}$ are most pronounced during the daytime.

As seen from Fig. 5, inclusion of vibrationally excited $\mathrm{N}_{2}$ and $\mathrm{O}_{2}$ brings the model and data into better agreement on 6,9 , and 10 April in comparison with the approaches of Eqs. (15) and (16). Both the daytime and nighttime densities are reproduced by the IZMIRAN model without the vibrationally excited nitrogen and oxygen in $L$ on 8 and 11 April. When $\mathrm{N}_{2}(v)$ is not included in the loss rate of the $\mathrm{O}^{+}\left({ }^{4} \mathrm{~S}\right)$ ions the agreement between the model and the data is the best on 7 April.

The IZMIRAN model with the vibrational states of $\mathrm{N}_{2}(v)$ and $\mathrm{O}_{2}(v)$ included does not always fit the data. This could be due to a number of factors, such as a possible inability of the MSIS- 86 model accurately to predict the detailed thermospheric response to this storm above Millstone Hill, uncertainties in EUV fluxes, rate coefficients, and the flow of ionization between the ionosphere and plasmasphere, and possible horizontal divergence of the flux of ionization above the station.

\subsection{Electron and ion temperatures}

Figure 6 shows the diurnal variations of the measured and modeled electron and ion temperatures at the F2peak altitude. The model results were obtained with $\mathrm{N}_{2}(v)$ and $\mathrm{O}_{2}(v)$ (solid lines) and when the approaches of Eqs. (15) (dashed-dotted lines) and (16) (dashed lines) are used in the IZMIRAN model for the loss rate of the $\mathrm{O}^{+}\left({ }^{4} \mathrm{~S}\right)$ ions. As can be seen, the effects on $T_{e}$ of adding $\mathrm{N}_{2}(v)$ and $\mathrm{O}_{2}(v)$ are largest during the day, with increases in $T_{e}$ accompanying the decreases in $\mathrm{NmF} 2$.

During the period 6-9 April the agreement between the measured and modeled temperatures is excellent. On 11 and 12 April the agreement is satisfactory for the ion temperature. The measured electron and ion temperatures are generally lower than the modeled electron and ion temperatures between 9:30 and 14:30 LT on 10 April when extremely low main $F$ peak altitudes were observed. The electron-ion cooling rate is proportional to the square of the electron density and therefore if the electron density is too large, the electron temperature is too small, as is apparent during the day on 10 April. The effects of $\mathrm{N}_{2}(v)$ and $\mathrm{O}_{2}(v)$ are negligible on the calculation of $T_{i}$ at the F-region altitudes except for the short time-periods around 9:30-14:30 LT on 10 April, when these changes in $T_{i}$ are caused by the variations of the main $\mathrm{F}$ peak altitude (see Fig. 5).

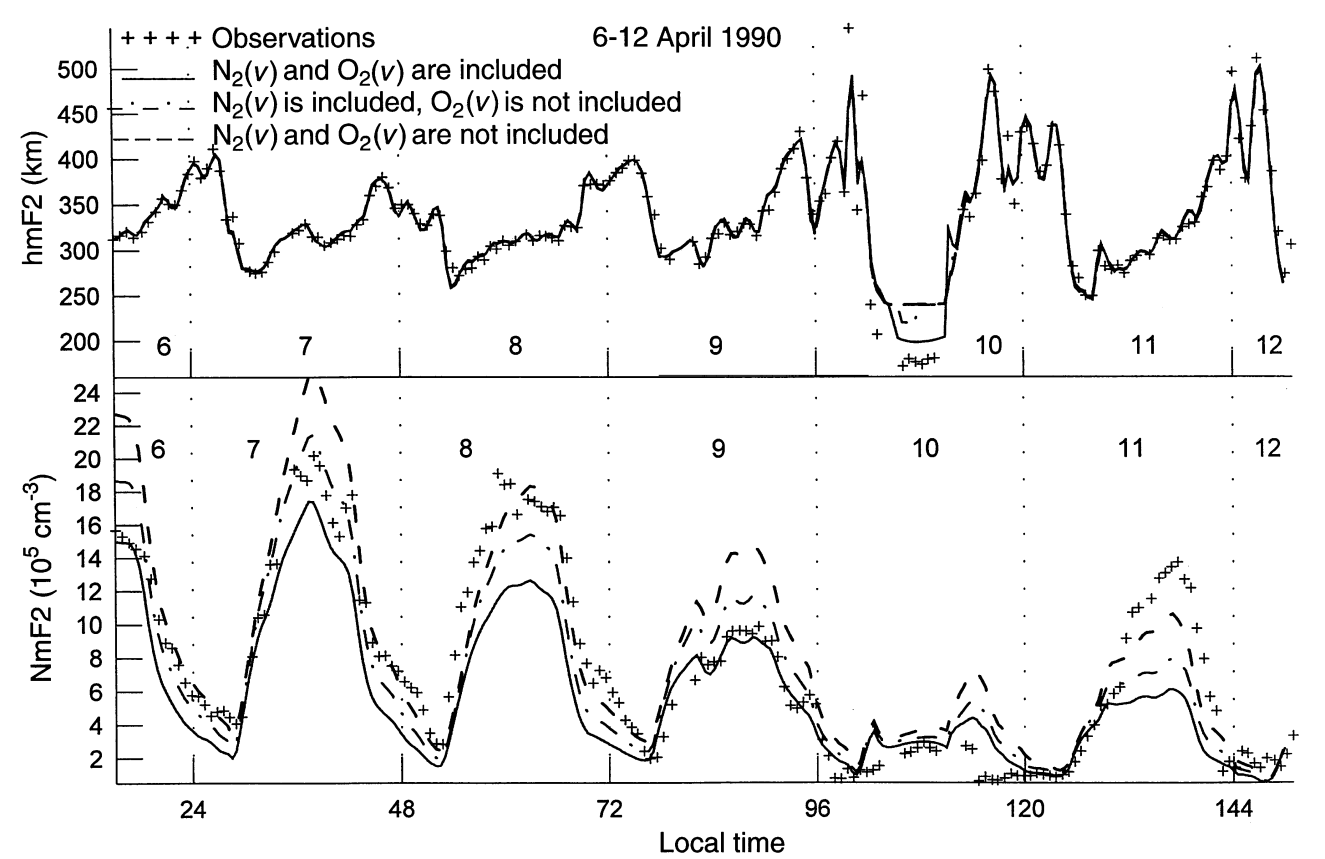

Fig. 5. Observed (crosses) and calculated F2 peak parameters above Millstone Hill for the magnetically quiet and disturbed period 6-12 April 1990. Top: hmF2, and bottom: NmF2. The MSIS-86 model with the adjusted atomic oxygen density is used in the IZMIRAN model between 07:00 and 15:00 LT on 10 April at all altitudes. The modeled $\mathrm{NmF} 2$ and hmF2 were obtained with effects of $\mathrm{N}_{2}(v)$ and $\mathrm{O}_{2}(v)$ using the non-Boltzmann populations of the first five vibrational levels by solving the $\mathrm{O}_{2}(v=1-5)$ time-dependent continuity equations (solid lines), and when $\mathrm{O}_{2}(v)$ was not included in the calculations (dasheddotted lines). The dashed lines give results without effects of $\mathrm{N}_{2}(v)$ and $\mathrm{O}_{2}(v)$ on the $\mathrm{O}^{+}\left({ }^{4} \mathrm{~S}\right)$ loss rate 


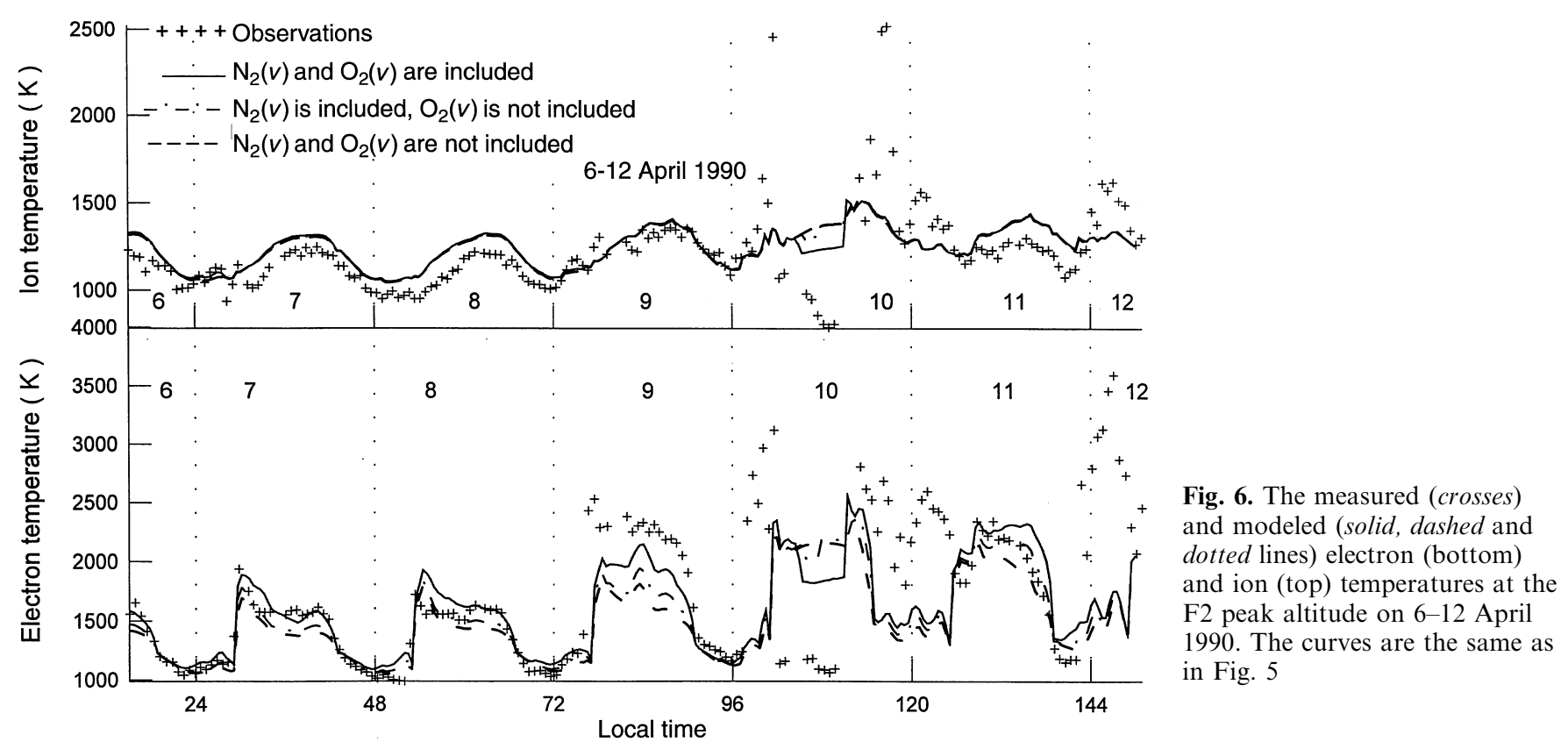

\subsection{Effects on electron density of possible errors in calculated neutral temperature and densities}

As Fig. 5 shows, there is large disagreement up to a factor of $2-3$ between the measured and modeled $\mathrm{NmF} 2$ during the quiet nighttime periods 6-8 April. This nighttime disagreement between the measured and modeled NmF2 was also found by Richards et al. (1994b) and Pavlov and Buonsanto (1997) for the 16-17 March 1990 undisturbed period and Pavlov and Buonsanto (1997) for the 6-8 April 1990 undisturbed period. Satisfactory agreement between the model and the data is obtained during the quiet intervals provided that the recombination rate of $\mathrm{O}^{+}\left({ }^{4} \mathrm{~S}\right)$ ions was decreased by a factor of 1.5 by decreasing the MSIS-86 $\mathrm{N}_{2}$ and $\mathrm{O}_{2}$ densities by 1.5 at all altitudes during the nighttime periods of the 17-18 March and 19-20 March 1990 and 6-8 April and 8-9 April 1990 in order to increase the NmF2 at night to match observations better (Pavlov and Buonsanto, 1997).

The MSIS-86 model was developed by Hedin (1987) by the improvement of the MSIS-77 model (Hedin et al., 1997). Before the MSIS-86 model was created many defects of the MSIS-77 model were removed by Kohnlein (1980) in his model of the neutral atmosphere (the K model). No measured densities were available during the 6-12 April 1990 period. Hence the comparison between modeled and measured NmF2 remains the only acceptable source to evaluate the ability of the MSIS-86 and K models to reproduce neutral density and temperature variations. The present investigation enables us to compare the measured $\mathrm{NmF} 2$ with the modeled $\mathrm{NmF} 2$ obtained by use the MSIS- 86 and $\mathrm{K}$ models to evaluate the effects of the uncertainty in the neutral temperature and densities on calculated electron densities.

Solid and dashed lines of Fig. 7 give the comparison of the modeled densities using the MSIS- 86 and K models. The model results were obtained when the atomic oxygen densities given by both models were decreased by a factor of 1.8 at all altitudes between 07:00 and 15:00 LT on 10 April. We can see that the MSIS-86 model gives the best agreement between measured and modeled NmF2 during the magnetic storm period 9-11 April. This results shows that during geomagnetic storms the more complicated MSIS-86 model, run using seven 3-h Ap indices, has an advantage in comparison with the $\mathrm{K}$ model, which uses one $3-\mathrm{h} \mathrm{Kp}$ index. However, the model results obtained by use the $\mathrm{K}$ model agree much better with the observations in comparison with using of the MSIS-86 model during the quiet daytime and nighttime periods 6-8 April, and there is good agreement between the modeled NmF2 and the data on 6-8 April if the $\mathrm{K}$ model is used. Our calculations indicate that a factor of 2 increase in theoretical undisturbed nighttime F2 peak electron density is due to a factor of 1.7-2 decrease in $\left[\mathrm{N}_{2}\right]$ and $\left[\mathrm{O}_{2}\right]$ given by the $\mathrm{K}$ model relative to the MSIS-86 $\left[\mathrm{N}_{2}\right]$ and $\left[\mathrm{O}_{2}\right]$ at hmF2.

The quiet period 6-8 April was a period of moderate solar activity. It is not clear whether the MSIS-86 model or the $\mathrm{K}$ model gives the best agreement between measured and modeled $\mathrm{NmF} 2$ during quiet conditions for other solar activity levels and seasons. We intend to solve these tasks in future studies.

\section{Conclusions}

The model results were compared to the Millstone Hill incoherent-scatter radar measurements of electron density and temperature for the geomagnetically quiet and disturbed period on 6-12 April 1990. The model used is an enhanced and updated version of the IZMIRAN model which we have steadily developed over the years. The updated model uses the revised rates of ionization of $\mathrm{O}, \mathrm{N}_{2}$, and $\mathrm{O}_{2}$ by secondary photoelectrons. The 


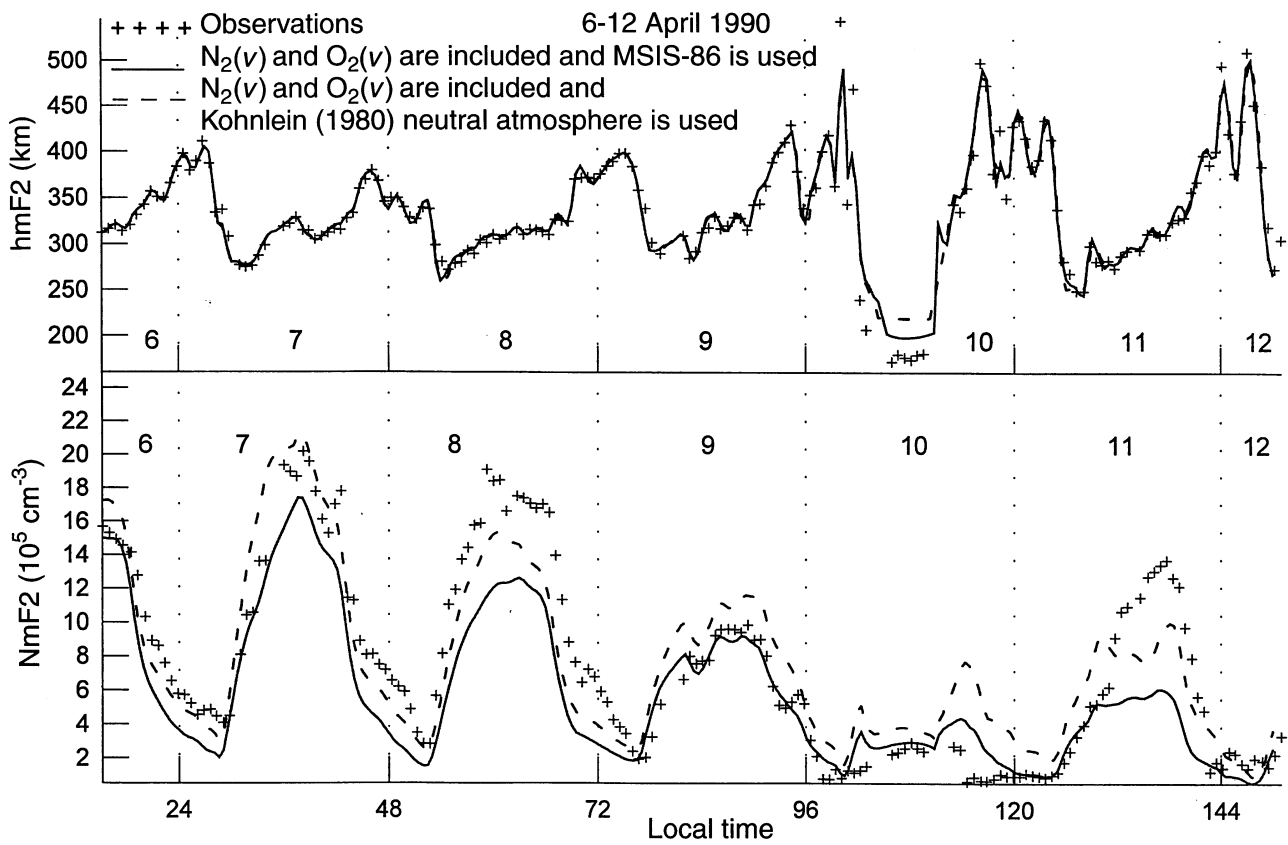

Fig. 7. Observed (crosses) and calculated $F 2$ peak parameters above Millstone Hill for the magnetically quiet and disturbed period 6-12 April, 1990. Top: hmF2, and bottom: $\mathrm{NmF} 2$. The solid lines are $\mathrm{hmF} 2$ and $\mathrm{NmF} 2$ when the MSIS-86 model is used, and dashed lines are $\mathrm{hmF} 2$ and $\mathrm{NmF} 2$ when the K model is used. The model results were obtained when the atomic oxygen densities of the MSIS- 86 and $\mathrm{K}$ models were decreased by a factor of 1.8 at all altitudes between 07.00 and 15.00 LT on 10 April major enhancement to the IZMIRAN model developed in this study is the use of the new loss rate of $\mathrm{O}^{+}\left({ }^{4} \mathrm{~S}\right)$ ions as a result of the new high-temperature flowing afterglow measurements of the rate coefficients for the reactions of $\mathrm{O}^{+}\left({ }^{4} \mathrm{~S}\right)$ with $\mathrm{N}_{2}$ and $\mathrm{O}_{2}$ given by Hierl et al. (1997). These new measurements do not support the Van Zandt and O'Malley (1973) theory and the assumption of Eq. (9) of similar translation dependencies for different states is reasonable for the use in models of the ionosphere.

Using the flowing afterglow measurements of the rate coefficient for the reactions of $\mathrm{O}^{+}\left({ }^{4} \mathrm{~S}\right)$ with $\mathrm{O}_{2}$ given by Hierl et al. (1977), we evaluated the approximate contribution of each vibrational state of $\mathrm{O}_{2}(v)$ and found the partial rate coefficients for vibrational quantum number $v=1-5$ which can be used in calculations of electron density.

The deviations from the Boltzmann distribution for the first five vibrational levels of $\mathrm{O}_{2}$ were calculated. The present study suggests that the deviations from the Boltzmann distribution are not significant. It was found that the non-Boltzmann distribution assumption and the difference between $T_{n}$ and $T_{i}$ can lead to the increase up to about $3 \%$ or the decrease up to about $4 \%$ of the calculated $\mathrm{NmF} 2$ in comparison with $\mathrm{NmF} 2$ calculated by using the approach of Eq. (11). So, we found that the use of Eq. (11) for $K_{2}$ gives NmF2 to sufficient accuracy during quiet and disturbed periods. The calculations also showed that the $\mathrm{O}_{2}$ and $\mathrm{N}_{2}$ vibrational temperatures during the quiet periods are less then during the magnetic storm periods. During the daytime the high vibrational temperatures stem from the enhanced thermal excitation of $\mathrm{O}_{2}$ and $\mathrm{N}_{2}$ as a result of high thermal electron temperatures at F2-region altitudes, while the decrease in the vibrational temperatures compared to the regular temperature is due to the decreases in the electron density and the neutral temperature.
We found that the inclusion of $\mathrm{N}_{2}(v>0)$ and $\mathrm{O}_{2}(v>0)$ in the calculations improves the agreement between the calculated $\mathrm{NmF} 2$ and the data on 6,9 , and 10 April. However, both the daytime and nighttime densities are reproduced by the IZMIRAN model without the vibrationally excited nitrogen and oxygen on 8 and 11 April better than the IZMIRAN model with $\mathrm{N}_{2}(v>0)$ and $\mathrm{O}_{2}(v>0)$. This could be due to a number of factors, such as possible uncertainties in neutral temperature and densities, EUV fluxes, rate coefficients, and the flow of ionization between the ionosphere and plasmasphere, and possible horizontal divergence of the flux of ionization above the station. Our calculations show that the increase in the $\mathrm{O}^{+}+\mathrm{N}_{2}$ rate factor due to the vibrationally excited nitrogen produces the $5-36 \%$ decrease in the calculated daytime peak density. The increase in the $\mathrm{O}^{+}+\mathrm{N}_{2}$ loss rate due to vibrationally excited $\mathrm{O}_{2}$ produces $8-46 \%$ reductions in $\mathrm{NmF} 2$. The effects of vibrationally excited $\mathrm{O}_{2}$ and $\mathrm{N}_{2}$ on $N_{e}$ and $T_{e}$ are most pronounced during the daytime.

The IZMIRAN model was unable to reproduce extremely low NmF2 and hmF2 (rather, it was the F1 peak) observed between 9:30 and 14:30 LT on 10 April when unadjusted MSIS-86 model densities were used, or when the MSIS-86 $\mathrm{N}_{2}$ and $\mathrm{O}_{2}$ densities were increased by a factor of 2 . However, the IZMIRAN model was able to reproduce this anomalous electron density event when the MSIS-86 atomic oxygen density was decreased by a factor of 1.8 between 07:00 and 15:00 LT on 10 April at all altitudes.

Model calculations were carried out using the MSIS86 and $\mathrm{K}$ models of neutral densities and temperature and the best agreement between the electron density measurements and the model results was obtained when the MSIS-86 model was used during the geomagnetic storm period 9-11 April. However, the model results obtained using the $\mathrm{K}$ model agree much better with the 
observations in comparison with using of the MSIS-86 model during the quiet daytime and nighttime periods 6-8 April.

\section{Appendix A}

\section{The effect of photoelectrons on ion densities}

The reactions of photoionization and the ionization due to photoelectrons of the neutral species, $\mathrm{N}_{2}, \mathrm{O}_{2}, \mathrm{O}$, and $\mathrm{He}$ are included in the IZMIRAN model. The production rates of ions by photoionization and due to photoelectrons are given by

$$
\begin{aligned}
& Q_{j}=n_{n} \sum_{\lambda} \sigma_{n j}(\lambda) \Phi_{\propto}(\lambda) \exp [-\tau(\lambda)], \\
& \Delta Q_{j}=n_{n} \int_{E_{n j}^{+}}^{\infty} \sigma_{n j}^{+}(E) F(E) \mathrm{d} E,
\end{aligned}
$$

where $n_{n}$ is the concentration of the $n$-th neutral gas, $\Phi_{\alpha}(\lambda)$ is the intensity of solar EUV radiation, $\lambda$ is a wavelength, $\sigma_{n j}(\lambda)$ is the photoionization cross section of the $n$-th neutral gas with the creation of the $j$-th ion, $\sigma_{n j}^{+}$is the cross section for collisions between energetic electrons and the $n$-th neutral gas, $F$, is the flux of photoelectrons, $E_{n j}^{+}$is the ionization threshold energy, $\tau(\lambda)=\sum_{n} n_{n} \sigma_{n}^{a}(\lambda) H_{n} C h_{n}(\chi), \sigma_{n}^{*}(\lambda)$ is the photoabsorption cross section of the $n$-th neutral gas, $H_{n}$ is the scale height of the $n$-th neutral gas, $C h_{n}(\chi)$ is the Chapman function, $\chi$ is a solar zenith angle.

The reaction of the ionization due to photoelectrons of the $n$-th neutral gas produces the $j$-th ions and photoelectrons with the energy $E=h c / \lambda-E_{n j}^{*}$ where $h$ is Plank's constant, $c$ is the light velocity, $E_{n j}^{*}$ is average energy losses of photoelectrons for ionization and excitation of neutral gases. The number of ions created by photoelectrons from each reaction of photoionization is $\left(h c / \lambda-E_{n j}^{*}\right) / E_{n j}^{*}$. As a result, the IZMIRAN model uses (Pavlov, 1994a)

$$
\Delta Q_{j}=d_{j} n_{n} \sum_{\lambda=0}^{\lambda_{n j}^{*}}\left(\lambda_{n j}^{*} / \lambda-1\right) \sigma_{n j}(\lambda) \Phi_{\propto}(\lambda) \exp [-\tau(\lambda)] \text {, }
$$

where $E_{n j}^{*}=32,30,22 \mathrm{eV}$ for $\mathrm{N}_{2}, \mathrm{O}_{2}$, and $\mathrm{O}$, and $\lambda_{n j}^{*}=h c / E_{n j}^{*}=38.7,41.3$, and $56.3 \mathrm{~nm}$, the correction factors $d_{j} \stackrel{n j}{=} 1.5,1.0,0.8,0.8$ and 0.8 for $j=\mathrm{O}_{2}^{+}, \mathrm{N}_{2}^{+}$, $\mathrm{O}^{+}\left({ }^{4} \mathrm{~S}\right), \mathrm{O}^{+}\left({ }^{2} \mathrm{D}\right)$, and $\mathrm{O}^{+}\left({ }^{2} \mathrm{P}\right)$ were calculated from comparison of the numerical results given by Oppenheimer et al. (1977) with the ratios of $\Delta Q_{j} / Q_{j}$ from Eqs. (A1), A3) in the limit $\tau=0$ for reference spectra SC21REF and F79050N and the photoionization cross sections given by Torr and Torr $(1982,1985)$.

In the updated IZMIRAN model described by Pavlov (1997), the solar EUV fluxes, $\Phi_{\propto}(\lambda)$, are obtained from the EUVAC model (Richards et al., 1994a) or EUV94X model (Tobiska 1993, 1994). The revised photoionization and photoabsorption cross sections are taken from Richards et al. (1994a).

If we use the EUVAC model with the 10.7 solar fluxes $\mathrm{F} 10.7=74$ and $\langle\mathrm{F} 10.7\rangle=87$, then in the limit $\tau=0$ the values of $\Delta Q_{j} / Q_{j}=0.34,0.49,0.56,0.28$, and 0.20 for $j=\mathrm{O}^{+}\left({ }^{4} \mathrm{~S}\right), \mathrm{O}^{+}\left({ }^{2} \mathrm{D}\right), \mathrm{O}^{+}\left({ }^{2} \mathrm{P}\right), \mathrm{N}_{2}^{+}(\mathrm{X}), \mathrm{O}_{2}^{+}(\mathrm{X})$. The full photoelectron calculation by Richards and Torr (1988), who employed the modified F74113 reference spectra, gave these secondary ions in the proportions of $0.56,0.24,0.20,0.36$, and 0.20 . Rees (1989) gives these proportions as $0.4,0.4,0.2,0.5$, and 0.17 .

To adjust $\Delta Q_{j} / Q_{j}$ from Eqs. (A1), (A3) to the full photoelectron calculations of Richards and Torr (1988) and Rees (1989), we use the new correction factors $d_{j}=1,1,1,2$, and 1 for $j=\mathrm{O}^{+}\left({ }^{4} \mathrm{~S}\right), \mathrm{O}^{+}\left({ }^{2} \mathrm{D}\right), \mathrm{O}^{+}\left({ }^{2} \mathrm{P}\right)$, $\mathrm{N}_{2}^{+}(\mathrm{X}), \mathrm{O}_{2}^{+}(\mathrm{X})$ and the old values of $\lambda_{n j}^{*}=38.7,41.3$, and $56.3 \mathrm{~nm}\left(E_{n j}^{*}=32,30\right.$, and $\left.22 \mathrm{eV}\right)$ for $j=\mathrm{N}_{2}^{+}, \mathrm{O}_{2}^{+}$ and $\mathrm{O}^{+}\left({ }^{4} \mathrm{~S}\right)$. In the model, the new average energy losses of photoelectrons are included as $E_{n j}^{*}=27.6$ and 35.6 $\mathrm{eV}$ and $\lambda_{n j}^{*}=45$ and $35 \mathrm{~nm}$ for $j=\mathrm{O}^{+}\left({ }^{2} \mathrm{D}\right)$ and $\mathrm{O}^{+}\left({ }^{2} \mathrm{P}\right)$. If we use the EUVAC model with the 10.7 solar fluxes $\mathrm{F} 10.7=74$ and $\langle\mathrm{F} 10.7\rangle=87$, then in the limit $\tau=0$ the values $\Delta Q_{j} / Q_{j}=0.42,0.37,0.20,0.37$, and 0.20 for $j=\mathrm{O}^{+}\left({ }^{4} \mathrm{~S}\right), \mathrm{O}^{+}\left({ }^{2} \mathrm{D}\right), \mathrm{O}^{+}\left({ }^{2} \mathrm{P}\right), \mathrm{N}_{2}^{+}(\mathrm{X})$, and $\mathrm{O}_{2}^{+}(\mathrm{X})$.

We believe that photoelectrons produce negligible amounts of $\mathrm{O}^{+}\left({ }^{4} \mathrm{P}\right)$ and $\mathrm{O}^{+}\left({ }^{2} \mathrm{P}^{*}\right)$ ions (Richards and Torr, 1988) which are included in the updated IZMIRAN model.

\section{Appendix B}

Continuity and energy equations for the vibrationally excited oxygen molecules

Pavlov (1989, 1994b) treated the vibrationally excited oxygen molecules as a set of harmonic and anharmonic oscillator energy levels. The Pavlov (1994b) study suggests that the effect of anharmonicity of $\mathrm{O}_{2}(j)$ on $\mathrm{O}_{2}(j)$ number densities, $n_{j}=\left[\mathrm{O}_{2}(j)\right]$, is small at the energy levels $j=1-5$. Therefore our model uses the system of equations given by Pavlov (1989) to determine $n_{j}(j=1-5)$ using the harmonic oscillator energy level approximation, the vibrational-vibrational and vibrational-translational energy exchange of $\mathrm{O}_{2}(j)$, the diffusion of $\mathrm{O}_{2}(j)$ in the mixture of $\mathrm{O}_{2}(0), \mathrm{N}_{2}$, and $\mathrm{O}$, and production rates, $\mathrm{Q}_{j}$, of $\mathrm{O}_{2}(j)$ as follows:

$$
\begin{gathered}
\frac{\partial}{\partial t} n_{j}+\frac{\partial}{\partial z} F_{j}=\left\{(j+1) n_{j+1}-[(j+1) \Theta+j] n_{j}+j \Theta n_{j-1}\right\} \tau_{v t}^{-1} \\
+\left\{(j+1)(1+\alpha) n_{j+1}-[(j+1) \alpha\right. \\
\left.+j(1+\alpha)] n_{j}+j \alpha n_{j-1}\right\} \tau_{v v}^{-1}+Q_{j}, \quad \text { (B1) } \\
\frac{\partial}{\partial t} \alpha-\frac{1}{n} \frac{\partial}{\partial z} D n \frac{\partial}{\partial z} \alpha=\frac{1}{n} \sum_{j} j Q_{j}-\left(\alpha-\frac{\Theta}{1-\Theta}\right) \tau_{v t}^{-1}, \quad \text { (B2) }
\end{gathered}
$$

where $t$ is the local time, $z$ is the altitude, $F_{j}=-D\left[\partial / \partial z n_{j}+n_{j}\left(1 / H+1 / T_{n} \partial / \partial z T_{n}\right)\right], n=\sum_{j} n_{j}$, the vibrational quanta $\alpha=\frac{1}{n} \sum_{j} j n_{j}, \Theta=\exp \left(-E_{i} T_{n}^{-1}\right)$, $H=k T_{n}(m g)^{-1}$, the vibrational temperature $T_{v i b}=$ $-E_{1} / \ln \left\{\alpha(1+\alpha)^{-1}\right\}, D$ is the diffusion coefficient of the vibrationally excited oxygen molecules, $m$ denotes the mass of $\mathrm{O}_{2}, g$ is the acceleration due to gravity, $E_{1}=2239 \mathrm{~K}$ is the energy of the first level of $\mathrm{O}_{2}$ given by Radzig and Smirnov (1980), $\tau_{v t}^{-1}=\left\{P_{1}[\mathrm{O}]+\right.$ $\left.P_{2}\left[\mathrm{~N}_{2}\right]+P_{3}\left[\mathrm{O}_{2}\right]\right\}(1-\Theta), \tau_{v v}^{-1}=K_{v v} n$. 
In calculating the times of the vibrational-translational (vt), $\tau_{v t}$, and vibrational-vibrational $(\mathrm{vv}), \tau_{v v}$, energy exchange we have adopted the measurement of the rate coefficient, $P_{1}$, of the vibrational-translational energy exchange $\mathrm{O}_{2}(j=1)-\mathrm{O}$ at temperatures $500 \leq T_{n} \leq 2050 \mathrm{~K} \quad$ as $\quad P_{1}=T_{n} /\left[2.24 \cdot 10^{14}+\right.$ $\left.3.36 \cdot 10^{7}\right] \exp \left(110 T_{n}^{-1 / 3}\right) \mathrm{cm}^{3} \mathrm{~s}^{-1}$ (Dushin et al., 1988). We use the rate coefficients $P_{2}$ of collisional vt-relaxation of $\mathrm{O}_{2}(1)$ by $\mathrm{N}_{2}(0)$ given by Parker and Ritke (1973) as $P_{2}=6.8 \cdot 10^{-19}\left(T_{n} / 300\right)^{0.5} \mathrm{~cm}^{3} \mathrm{~s}^{-1}$. The rate coefficient $P_{3}$ of the vt-exchange $\mathrm{O}_{2}(1)-\mathrm{N}_{2}(0)$ and the rate coefficient $K_{v v}$ of the vv-exchange $\mathrm{O}_{2}(1)-\mathrm{O}_{2}(0)$ were calculated by Billing and Kolesnick (1992). We have approximated these numerical calculations as $P_{3}=2.7 \cdot 10^{-18}$ $\left(T_{n} / 300\right)^{6.5} \mathrm{~cm}^{3} \mathrm{~s}^{-1}$ and $K_{v v}=6.7 \cdot 10^{-16} T_{n} \mathrm{~cm}^{3} \mathrm{~s}^{-2}$ (Pavlov, 1994b).

It is required to know the value of $n_{6}$ to calculate the value of $n_{5}$ from Eqs. (B1) and (B2), and by analogy with the Boltzmann distribution the condition $n_{6}=n_{5} \alpha(1+\alpha)^{-1}$ is assumed. The diffusion coefficients of vibrationally excited molecules are not sensitive to the number of energy level (Fujimoto et al., 1976) and we can use

$$
\begin{aligned}
\mathrm{D}= & \mathrm{Y}\left\{[\mathrm{O}]\left(\mathrm{D}\left(\mathrm{O}_{2}, \mathrm{O}\right)\right)^{-1}+\left[\mathrm{N}_{2}\right]\left(\mathrm{D}\left(\mathrm{O}_{2}, \mathrm{~N}_{2}\right)\right)^{-1}\right. \\
& \left.+\left[\mathrm{O}_{2}\right]\left(D\left(\mathrm{O}_{2}, \mathrm{O}_{2}\right)\right)^{-1}\right\}^{-1},
\end{aligned}
$$

where $Y=[\mathrm{O}]+\left[\mathrm{N}_{2}\right]+\left[\mathrm{O}_{2}\right]$, the binary diffusion coefficients of the unexcited $\mathrm{O}_{2}$ molecules (Pavlov, 1981) $D\left(\mathrm{O}_{2}, \mathrm{O}\right)=9.69 \cdot 10^{16} \cdot T_{n}^{0.774} Y^{-1}$ and $D\left(\mathrm{O}_{2}, \mathrm{~N}_{2}\right)=$ $8.29 \cdot 10^{16} \cdot T_{n}^{0.724} Y^{-1}$ the self-diffusion coefficient of $\mathrm{O}_{2}$ is the function of the molecule oxygen viscosity coefficient (Ferziger and Kaper, 1972) and can be calculated as $D\left(\mathrm{O}_{2}, \mathrm{O}_{2}\right)=10^{17} \cdot T_{n}^{0.69} Y^{-1}$, the units of $[\mathrm{O}],\left[\mathrm{O}_{2}\right]$ and $\left[\mathrm{N}_{2}\right]$ are $\mathrm{cm}^{-3}$ and the units of $\mathrm{D}$ are $\mathrm{cm}^{2} \mathrm{~s}^{-1}$.

The vibrationally excited oxygen molecules may be produced in the following processes at E- and F-region altitudes:

$\mathrm{O}_{2}(j=0)+e_{t} \leftrightarrow \mathrm{O}_{2}^{-2} \Pi_{g}(i>4) \leftrightarrow \mathrm{O}_{2}(j>0)+e_{t}$,

$\mathrm{O}\left({ }^{1} \mathrm{D}\right)+\mathrm{O}_{2}(0) \rightarrow \mathrm{O}\left({ }^{3} \mathrm{P}\right)+\mathrm{O}_{2}(j>0)$.

During the vibrational excitation of the unexcited $\mathrm{O}_{2}(j=0)$ by electron impact the temporary capture of the electron occurs to form the excited ion $\mathrm{O}_{2}^{-2} \Pi_{g}$ at vibrational level $i$, with the following vibrational excitation of $\mathrm{O}_{2}$. The production rates of $\mathrm{O}_{2}(j)$ due to the thermal electron excitation of $\mathrm{O}_{2}(0)$ and the deexcitation of $\mathrm{O}_{2}(j)$ in the reactions of (B4) can be calculated as (Pavlov, 1997, 1998b)

$$
\begin{aligned}
Q_{j 1}= & \sqrt{8}\left(k T_{e} \pi m_{e}\right)^{-0.5} \mathrm{~N}_{e}\left\{\left[\mathrm{O}_{2}(0)\right]\right. \\
& \left.-\left[\mathrm{O}_{2}(j)\right] \exp \left(j E_{1} T_{e}^{-1}\right)\right\} \sum_{i=5}^{24} S_{i j} X_{i} \exp \left(-X_{i}\right),
\end{aligned}
$$

where $k$ is Boltzmann's coefficient, $m_{e}$ denotes the mass of electrons, $i$ is the number of the $\mathrm{O}_{2}^{-} 2 \Pi_{g}$ vibrational level, $S_{i j}$ is the integral vibrational - excitation cross section for the sharp peak in the vibrational cross section at the energy $E_{i}^{*}$ measured by Allan (1995), $X_{i}=E_{i}^{*}\left(k T_{e}\right)^{-1}, E_{i}^{*}$ is the energy of the incident electron at the center of the $\mathrm{O}_{2}^{-} 2 \Pi_{g}$ resonance given by Allan (1995), the analytical expressions describing the dependence in Eq. (B6) of $Q_{j 1}$ from $T_{e}$ available to the researcher for quick reference and accurate computer modeling with a minimum of calculations are given by Pavlov (1998b).

There are no measurements of the rate coefficient dependence of the reaction (B5) on the vibrational level number, and we assume that the probability of $\mathrm{O}_{2}(j)$ creation in the reaction (B5) is the same for levels $j=1-3$ (Pavlov, 1994b):

$Q_{j 2}=\varepsilon_{j} K\left[\mathrm{O}\left({ }^{1} D\right)\right]\left[\mathrm{O}_{2}(0)\right]$,

where $\varepsilon_{j}=1 / 3$ for $j=1-3, \varepsilon_{j}=0$ for $j>3, K=$ $6.4 \cdot 10^{-12} \exp \left(67 / T_{n}\right) \mathrm{cm}^{3} \mathrm{~s}^{-1}$.

The production rates of $\mathrm{O}_{2}(j)$ are given as $Q_{j}=Q_{j 1}+Q_{j 2}$.

Solving the system of Eqs. (B1), (B2), the model can calculate the number densities of vibrational excited molecular oxygen determining the real non-Boltzmann distribution of $\mathrm{O}_{2}(j)$. The model includes the option to use the model of the Boltzmann distributions, $n_{j B}$, of vibrationally excited molecular oxygen given by Eqs. (12) and (B2). At the lower boundary $(120 \mathrm{~km})$ the diffusion processes of vibrationally excited molecules and vibrational quanta are neglected in the northern and southern hemispheres. The upper boundary conditions are assumed as $\frac{\partial}{\partial z} \alpha=0$, and $F_{j}=0$ at $700-\mathrm{km}$ altitude.

Acknowledgements. The research described in this publication was supported by grant 96-05-64031 from the Russian Foundation of the Fundamental Researches. The author appreciates the contribution of data by M. Buonsanto, J. Foster, and other personnel at Millstone Hill Observatory of the Massachusetts Institute of Technology. I would like to thank anonymous referees for critical reading of the manuscript as reviewers and for helpful comments.

Topical Editor D. Alcaydé thanks W.-R. Hoegy and J. Grebowsky for their help in evaluating this paper.

\section{References}

Abdou, W. A., D. G. Torr, P. G. Richards, M. R. Torr, and E. L. Breig, Results of a comprehensive study of the photochemistry of $\mathrm{N}_{2}^{+}$in the ionosphere, J. Geophys. Res., 89, 90699079, 1984.

Albritton, D. L., I. Dotan, W. Lindinger, M. McFarland, J. Tellinghuisen, and F. C. Fehsenfeld, Effects of ion speed distributions in flow-drift tube studies on ion-neutral reactions, J. Chem. Phys., 66, 410-421, 1977.

Allan, M., Measurement of absolute differential cross sections for vibrational excitation of $\mathrm{O}_{2}$ by electron impact, J. Phys. B., 28, 5163-5175, 1995.

Banks, P. M., Collision frequencies and energy transfer electrons, Planet. Space Sci., 14, 1085-1090, 1966.

Billing, G. D., and R. E. Kolesnick, Vibrational relaxation of oxygen. State to state rate constants, Chem. Phys. Lett., 200, 382-386, 1992.

Buonsanto, M. J., J. C. Foster, and D. P. Sipler, Observations from Millstone Hill during the geomagnetic disturbances of March and April 1990, J. Geophys. Res., 97, 1225-1243, 1992. 
Buonsanto, M. J., D. P. Sipler, G. V. Davenport, and J. M. Holt, Estimation of the $\mathrm{O}^{+}, \mathrm{O}$ collision frequency from coincident radar and Fabry Perot observations at Millstone Hill, J. Geophys. Res., 102, 17267-17274, 1997.

Burnside, R. G., C. A. Tepley, and V. B. Wickwar, The $\mathrm{O}^{+}-\mathrm{O}$ collision cross-section : can it be inferred from aeronomical measurements? Ann. Geophysicae, 5, 343-350, 1987.

Chen, A., R. Johnsen, and M. A. Biondi, Measurements of the $\mathrm{O}^{+}+\mathrm{N}_{2}$ and $\mathrm{O}^{+}+\mathrm{O}_{2}$ reactions rates from 300 to $900 \mathrm{~K}$, Chem. Phys., 69, 2688-2691, 1978.

Dushin, V. K., I. E. Zabelenskij, and O. V. Shatalov, Desactivation of the molecular oxygen vibration (in Russian), Chem. Phys., 7, 1320-1327, 1988.

Ferguson, E. E., N. G. Adams, D. Smith, and E. Alge, Rate coefficients at $300 \mathrm{~K}$ for the vibrational energy transfer reactions from $\mathrm{N}_{2}(v=1)$ to $\mathrm{O}_{2}^{+}(v=0)$ and $\mathrm{NO}^{+}(v=0)$, J. Chem. Phys., 80, 6095-6098, 1984.

Ferziger, J. H., and G. H. Kaper, Mathematical theory of transport processes in gases, North-Holland Physics, Amsterdam, London, 1972.

Fox, J. L., and A. Dalgarno, The vibrational distribution of $\mathrm{N}_{2}^{+}$in the terrestrial ionosphere, J. Geophys. Res., 90, 7557-7567, 1985.

Fujimoto, G., A. Nitzan, and E. Weitz, Diffusion of vibrationally excited molecules, Chem. Phys., 15, 217-225, 1976.

Hedin, A. E., MSIS-86 thermospheric model, J. Geophys. Res., 92, 4649-4662, 1987.

Hedin, A. E., S. A. Reber, J. P. Newton, et al., A global thermospheric model based on mass spectrometer and incoherent data MSIS:2. composition, J. Geophys. Res., 82, 2148-2156, 1977.

Hierl, M. P., I. Dotan, J. V. Seeley, J. M. Van Doren, R. A. Morris, and A. A. Viggiano, Rate constants for the reactions of $\mathrm{O}^{+}$with $\mathrm{N}_{2}$ and $\mathrm{O}_{2}$ as a function of temperature (300-1800 K), J. Chem. Phys., 106, 3540-3544, 1997.

Kirby, K. E., E. R. Constantinides, S. Babeu, M. Oppenheimer, and G. A. Victor, Photoionization and photoabsorption cross sections of thermospheric species: $\mathrm{He}, \mathrm{O}, \mathrm{N}_{2}$, and $\mathrm{O}_{2}$, At. Data Nucl. Data Tables, 23, 63-81, 1979.

Kohnlein, W., A model of thermospheric temperature and composition, Planet. Space Sci., 28, 225-243, 1980.

McFarland, M., D. L. Albritton, F. C. Fehsenfeld, E. E. Ferguson, and A. L. Schmeltekopf, Flow-drift technique for ion mobility and ion-molecule reaction rate constant measurements, II. positive ion reaction of $\mathrm{N}^{+}, \mathrm{O}^{+}$, and $\mathrm{N}_{2}^{+}$with $\mathrm{O}_{2}$ and $\mathrm{O}^{+}$with $\mathrm{N}_{2}$ from thermal to $2 \mathrm{eV}, J$. Chem. Phys., 59, 6620-6628, 1973.

Nisbet, J. S., Stehle, K., and E. Bleuler, Initial tests of an index based on AL values for modeling magnetic storm related perturbations of the thermosphere, J. Geophys. Res., 88, 21752180, 1983.

Oppenheimer, M., E. R. Constantinides, K. Kirby-Docken, G. A. Victor, and A. Dalgarno, Ion photochemistry of the thermosphere from Atmosphere Explorer C measurements, J. Geophys. Res., 82, 5485-5492, 1977.

Parker, J. G., and P. N. Ritke, Vibrational relaxation times of oxygen in the pressure range $10-100 \mathrm{~atm}$, J. Chem. Phys., 58, 314-323, 1973.

Pavlov, A. V., The binary molecular diffusion coefficients of the neutral components of the upper atmospheres of Earth, Mars, and Venus (in Russian), Space Res., 19, 82-86, 1981.

Pavlov, A. V., Rate coefficient of $\mathrm{O}^{+}$with vibrationally excited $\mathrm{N}_{2}$ in the ionosphere (in Russian), Geomagn. Aeron., 26, 166-168, 1986.

Pavlov, A. V., On the $\mathrm{O}_{2}^{*}$ content in the upper atmosphere and the effect of $\mathrm{N}_{2}^{*}$ and $\mathrm{O}_{2}^{*}$ on the electron density (in Russian), Geomagn. Aeron., 29, 818-823, 1989.

Pavlov, A. V., The role of vibrationally excited nitrogen in the formation of the mid-latitude ionospheric storms, Ann. Geophysicae, 12, 554-564, 1994a.

Pavlov, A. V., The role of vibrationally excited oxygen and nitrogen in the $\mathrm{D}$ and $\mathrm{E}$ regions of the ionosphere, Ann. Geophysicae, 12, 1086-1090, 1994b.
Pavlov, A. V., Mechanisms of the electron density depletion in the SAR arc region, Ann. Geophysicae, 14, 211-221, 1996.

Pavlov, A. V., Subauroral red arcs as a conjugate phenomenon: comparison of OVI-10 satellite data with numerical calculations, Ann. Geophysicae, 15, 984-998, 1997.

Pavlov, A. V., New electron energy transfer rates for vibrational excitation of $\mathrm{N}_{2}$, Ann. Geophysicae, 16, in press, 1998a.

Pavlov, A. V., New electron energy transfer and cooling rates by excitation of $\mathrm{O}_{2}$, Ann. Geophysicae, 16, 176-182, $1998 \mathrm{~b}$.

Pavlov, A. V., and M. J. Buonsanto, Comparison of model electron densities and temperatures with Millstone Hill observations during undisturbed periods and the geomagnetic storms of 1623 March and 6-12 April 1990, Ann. Geophysicae, 15, 327-344, 1997.

Pavlov, A. V., M. J. Buonsanto, A. C. Schlesier, and P. G. Richards, Comparison of models and data at Millstone Hill during the June 5-11, 1991 storm, J. Geophys. Res., 102, in press, 1998.

Pesnell, W. D., K. Omidvar, and W. R. Hogey, Momentum transfer collision frequency of $\mathrm{O}^{+}-\mathrm{O}$, Geophys. Res. Lett., 20, 13431356, 1993.

Prolss, G. W., Magnetic storm associated perturbations of the upper atmosphere: recent results obtained by satellite-borne gas analyzers, Rev. Geophys. Space Phys., 18, 183-202, 1980.

Radzig, A. A., and B. V. Smirnov, The reference book in atomic and molecular physics (in Russian), Atomizdat, Moscow, 1980.

Rees, M. H., Physics and chemistry of the upper atmosphere, Cambridge University Press, New York, 1989.

Richards, P. G., An improved algorithm for determining neutral winds from the height of the F2 peak electron density, J. Geophys. Res., 96, 17839-17846, 1991.

Richards, P. G., and D. G. Torr, A factor of 2 reduction in theoretical F2 peak electron density due to enhanced vibrational excitation of $\mathrm{N}_{2}$ in summer at solar maximum, J. Geophys. Res., 91, 11331-11336, 1986.

Richards, P. G., and D. G. Torr, Ratios of photoelectron to EUV ionization rates for aeronomic studies, J. Geophys. Res., 93, 4060-4066, 1988.

Richards, P. G., J. A. Fennelly, and D. G. Torr, EUVAC : a solar EUV flux model for aeronomical calculations, J. Geophys. Res., 99, 8981-8992, 1994a. (Correction in J. Geophys. Res., 99, 13283, 1994.)

Richards, P. G., D. G. Torr, M. J. Buonsanto, and D. P. Sipler, Ionospheric effects of the March 1990 magnetic storm: comparison of theory and measurements, J. Geophys. Res., 99, 23359-23365, 1994b.

Samson, J. A. R., Z. X. He, L. Yin, and G. N. Haddad, Precision measurements of the absolute photoionization cross sections of He, J. Phys. B : At. Mol: Opt. Phys., 27, 887-898, 1994.

Schmeltekopf, A. L., E. E. Ferguson, and F. C. Fehsenfeld, Afterglow studies of the reactions $\mathrm{He}^{+}, \mathrm{He}\left(2^{3} \mathrm{~S}\right)$, and $\mathrm{O}^{+}$ with vibrationally excited $\mathrm{N}_{2}$, J. Chem. Phys, 48, 2966-2973, 1968.

St. -Maurice, J. -P., and D. G. Torr, Nonthermal rate coefficients in the ionosphere: the reactions of $\mathrm{O}^{+}$with $\mathrm{N}_{2}, \mathrm{O}_{2}$ and $\mathrm{NO}$, J. Geophys. Res., 83, 969-977, 1978.

Tobiska, W. K., The empirical solar EUV irradiance model EUV 94 (abstract), EOS Trans. AGU, 74(43), 490, 1993.

Tobiska, W. K., Modeled soft X-ray solar irradiance, Solar Phys., 152, 207-215, 1994.

Torr, M. R., and D. G. Torr, The role of metastable species in the thermosphere, Rev. Geophys. Space Phys., 20, 91-144, 1982.

Torr, M. R., and D. G. Torr, Ionization frequencies for solar cycle 21: revised J. Geophys. Res., 90, 6675-6678, 1985.

Van Zandt, T. E., and T. F. O'Malley, Rate coefficient for the reaction of $\mathrm{O}^{+}$with vibrationally excited $\mathrm{N}_{2}$, J. Geophys. Res., 78, 6818-6820, 1973.

Viehland, L. A., and E. A. Mason, Statistical - mechanical theory of gaseous ion - molecule reaction in an electrostatic field, J. Chem. Phys., 66, 422-434, 1977. 